\title{
DESEMPENHO, COMPOSIÇÃO CORPORAL E EXIGÊNCIAS LÍQUIDAS DE ENERGIA E PROTEÍNA DE TOURINHOS DE DOIS TIPOS GENÉTICOS ALIMENTADOS COM DIETAS DE ALTO TEOR DE CONCENTRADO
}

\section{MARIA LUISA DE MEDEIROS BULLE Zootecnista}

\author{
Orientador: Prof. Dr. Dante Pazzanese D.Lanna
}

Dissertação apresentada à Escola Superior de Agricultura "Luiz de Queiroz",

Universidade de São Paulo, para obtenção do título de Mestre em Agronomia, Área de Concentração: Ciência Animal e Pastagens.

\section{PIRACICABA}

Estado de São Paulo - Brasil

$$
\text { Julho - } 2000
$$




\section{ERRATA}

\section{No início da página 20 faltam as seguintes palavras:}

Os alimentos foram fornecidos na forma de ração completa, em duas refeições diárias e amostras de alimentos e sobras coletadas para análise. O teor de matéria

Na página 21 as colunas referentes aos tipos genéticos estão trocadas (Britânicos por Continentais). A seguir está a tabela corrigida:

Tabela 2. Efeito do nivel de fibra no desempenho de animais Britânicos e Continentais

Tabie 2. riffect of tevel of fiber on fecdlot performance of Bimsh and Coninertal young bulls

\begin{tabular}{|c|c|c|c|c|c|c|c|}
\hline \multirow[t]{3}{*}{ Varivicis } & \multirow{2}{*}{\multicolumn{3}{|c|}{$\begin{array}{l}\text { Nivel de } B I N^{1} \\
\text { Lerel of } B I N^{2}\end{array}$}} & \multirow{2}{*}{\multicolumn{2}{|c|}{$\begin{array}{l}\text { Ifpen (iencticos } \\
\text { Genelic groups }\end{array}$}} & \multirow{3}{*}{$\begin{array}{l}\text { interacto } \\
\text { RxF }\end{array}$} & \multirow[t]{3}{*}{$\mathrm{CV}^{3}$} \\
\hline & & & & & & & \\
\hline & $9 \%$ & $15 \%$ & $210^{\circ}$ & $\mathrm{B}^{3}$ & $\mathrm{C}^{4}$ & & \\
\hline Número de Animais & 12 & 12 & 12 & 18 & 18 & & \\
\hline \multicolumn{8}{|l|}{ Number of amimots } \\
\hline Periodo Experimental (dias) & 139 & 139 & 139 & 139 & 139 & & \\
\hline \multicolumn{8}{|l|}{ Dass of fixparinen } \\
\hline Peso Inicial (kg) & $260,3^{n}$ & $258,9^{\mathrm{a}}$ & $252,6^{\mathrm{a}}$ & $256,0^{2}$ & $258,5^{2}$ & 0,37 & 3,64 \\
\hline \multicolumn{8}{|l|}{ lnicial Weight } \\
\hline Peso final $(\mathrm{kg})$ & $426,8^{a b}$ & $448,7^{n}$ & $424,8^{\mathrm{t}}$ & $428.1^{2}$ & $438,4^{\bullet}$ & 0,40 & 3,52 \\
\hline \multicolumn{8}{|l|}{ Final Hezght } \\
\hline Ganho Peso Vivo (kp/dia) & $1,20^{3 t}$ & $1,36^{\prime \prime}$ & $1.24^{\mathrm{eb}}$ & $1,24^{n}$ & $1,29^{\mathrm{a}}$ & 0,80 & 7,57 \\
\hline \multicolumn{8}{|l|}{ 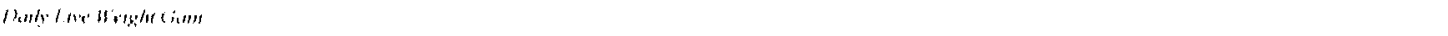 } \\
\hline Consumo Matéria Seca (kg MS/dia) & $6.85^{\mathrm{tr}}$ & $7,93^{\star}$ & $7,34^{\text {sb }}$ & $7,20^{\mathrm{n}}$ & $7,54^{*}$ & 0,57 & 7.69 \\
\hline Dre Matiartntake & & & & s & & & \\
\hline C'imsumes, "en de l'ceso Vives & $1, \%)^{4}$ & $2,24^{\pi}$ & $216^{4+1}$ & $2,11^{*}$ & $2.16^{*}$ & 1,82 & 7.23 \\
\hline \multicolumn{8}{|l|}{ Iny Matler Intake, o/n LW } \\
\hline Efficiencia (kg GPV/kg MS) & $0,176^{\mathrm{n}}$ & $0,172^{\mathrm{n}}$ & $0,169^{2}$ & $0,170^{\mathrm{A}}$ & $0,170^{2}$ & 0,82 & 7,48 \\
\hline Efficienas & & & & & & & \\
\hline
\end{tabular}

Na página 24, a tabela 3 está com o título errado e as colunas referentes aos tipos genéticos estão trocadas (Britânicos por Continentais). A seguir está a tabela corrigida:

Tabela 3. Efeito do nível de fibra no peso de órgãos de animais Britânicos e Continentais.

\begin{tabular}{|c|c|c|c|c|c|c|c|}
\hline \multirow[t]{3}{*}{ Variáveis } & \multirow{2}{*}{\multicolumn{3}{|c|}{$\begin{array}{l}\text { Nivel de } \mathrm{BN}{ }^{1} \\
\text { Level of } B I N^{2}\end{array}$}} & \multirow{2}{*}{\multicolumn{2}{|c|}{$\begin{array}{l}\text { Tipos Genéticos } \\
\text { Genetic gromips }\end{array}$}} & \multirow{3}{*}{$\begin{array}{l}\text { Intetaçào } \\
\qquad \mathrm{RxF}^{6}\end{array}$} & \multirow[t]{3}{*}{$\mathrm{CV}^{\prime}$} \\
\hline & & & & & & & \\
\hline & $3^{\circ} \%$ & $15^{\circ} \mathrm{o}$ & $21^{\circ} \pi$ & \multirow{3}{*}{$\frac{\mathrm{B}^{1}}{18}$} & \multirow{3}{*}{$\frac{C^{-1}}{18}$} & & \\
\hline Número de animaís & 12 & 12 & 12 & & & & \\
\hline Number of animals & & & & & & & \\
\hline periodo experimental (dias) & 139 & 139 & 139 & 139 & 139 & . & \\
\hline Dats of experment dirbs & & & & & & & \\
\hline Pero dos Rins (kg) & 0.85 & 0,83 & 0,87 & 0,82 & 0,88 & 0,05 & 13,8 \\
\hline kidrey wetght & & & & & & & \\
\hline Peso do Figado (kg) & 5,54 & 5,76 & 5.56 & 5,48 & 5.69 & 0,03 & 10,8 \\
\hline fNer wetght & & & & & & & \\
\hline PCso dos Rins \% PVG & 0.19 & 0,19 & 0.21 & 0.19 & 0.20 & 0,18 & 15.4 \\
\hline Nidney nelght $\$ 6$ L.W & & & & & & & \\
\hline Peso do Figado of PVf & 1,27 & 1,29 & 1.31 & 1,28 & 1,30 & 0,11 & 11,3 \\
\hline Liver Weight $96 \mathrm{l}, \mathrm{H}$ & & & & & & & \\
\hline
\end{tabular}




\section{Dados Internacionais de Catalogação na Publicação (CIP) DIVISÃO DE BIBLIOTECA E DOCUMENTAÇÃO - Campus "Luiz de Queiroz"/USP}

Bulle, Maria Luisa de Medeiros

Desempenho, composição corporal e exigências liquidas de energia e proteina de tourinhos de dois tipos genéticos alimentados com dietas de alto teor de concentrado / Maria Luisa de Medeiros Bulle. -- Piracicaba, 2000.

$50 \mathrm{p}$.

Dissertação (mestrado) - - Escola Superior de Agricultura Luiz de Queiroz, 2000. Bibliografia.

1. Alimento concentrado 2. Composição corporal 3. Crescimento animal 4. Desempenho animal 5. Dieta animal 6. Exigência liquida animal 7. Exigência nutricional 8. Touro I. Título 


\section{Dedico}

À meus pais, Giovanna e Antonio Augusto pelo exemplo de trabalho e força de vontade. E a meus queridos irmãos Lygia, Antonio e André pelo nosso grande amor

Ao Xi por toda a felicidade que nos une e à nossa Mariana que deu hoje seu primeiro sorriso largo

\section{Ofereço}

A dois grandes agrônomos, dois grandes amigos e dois grandes incentivadores;

Ao Sérgio Raposo de Medeiros, meu querido mentor

Ao Caríssimo "Seo "Alexandre von Prizelwitz (in memorian)

"As pessoas que nos são caras estão continuamente presentes, mesmo que o silêncio ou a distância as separem" 


\section{Agradecimentos}

Ao Professor Doutor Dante Pazzanese Lanna pela orientação, pela oportunidade de trabalharmos juntos e pela amizade;

Ao Professor Doutor Paulo Roberto Leme pelo auxílio na parte experimental e principalmente por toda sua gentileza;

Ao Professor Doutor Evaldo Lencioni Titto pelo auxilio durante a parte experimental;

Ao Fábio Garcia Ribeiro pela amizade e bons tempos de trabalho em Pirassununga;

A Ana Espasandin pelo grande auxilio na parte estatística deste trabalho;

Ao Dr. Eduardo Delgado pela grande ajuda no laboratório;

Aos funcionários da FZEA, Edilson, "Alemão", Ricardo, Marquinho, Estela e Érica; e aos funcionários do IZ - Nova Odessa, "Muzambinho", Dona Olinda, José e "Seo"

Pedro, pela colaboração e auxílio durante as diversas fases do trabalho;

Aos estagiários Marilene, Marianna, Juliano, "Sarita", "Minhoca", "Braquiária",

"Lumbriga", Rufino, "Riba" pela amizade e colaboração eficiente que fez toda a diferença;

Às amigas Ione, Fernanda e Paulinha, minhas queridas anfitriãs em Pirassununga;

À Fê e Anita grandes companheiras de todas as horas desses dois anos;

Aos amigos "Biológico", Brígida, Carmo, Dimas, Eduardo, Elaine, Fernanda, "Guzerá", Juliano, "Lua", Lili, Rafael, Ribamar, Sérgio, Tuka. Por todo incentivo, atenção, respeito, carinho, amizade. Por todos os bons momentos juntos que fizeram os dias de trabalho tão especiais;

À Eliana e Sílvia pelo auxílio com as referências Bibliográficas; À todos que de uma forma ou de outra colaboraram para a execução deste trabalho; Ao CNPq pela concessão da bolsa de estudos. 


\section{SUMÁRIO}

Página

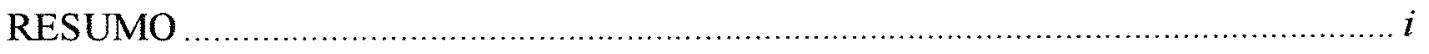

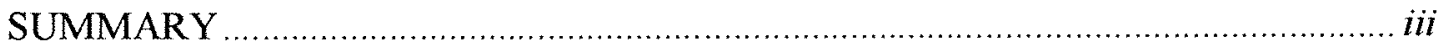

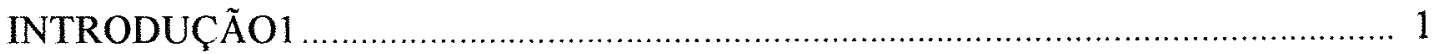

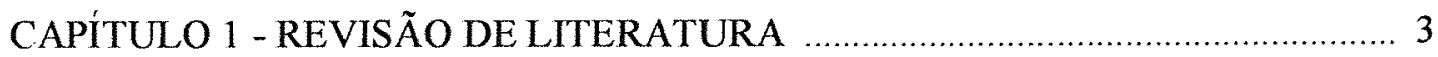

Tipos Genéticos, Exigências Nutricionais, Composição Química Corporal ................. 3

Dietas de Alto Teor de Concentrado ...................................................................... 7

Bagaço de Cana - de - Açúcar in natura ......................................................................... 11

CAPÍTULO 2 - BAGAÇO DE CANA - DE - AÇUCAR COMO ÚNICO VOLUMOSO

EM DIETAS DE ALTO TEOR DE CONCENTRADO. 1. DESEMPENHO …............ 14

Resumo

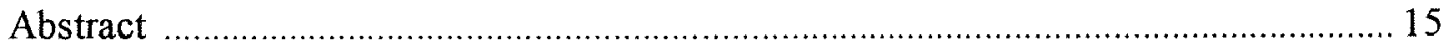

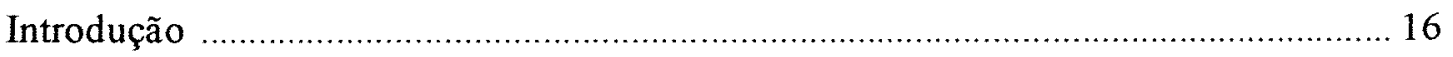

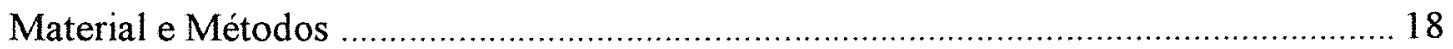

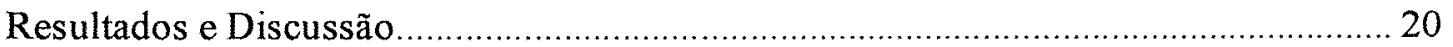

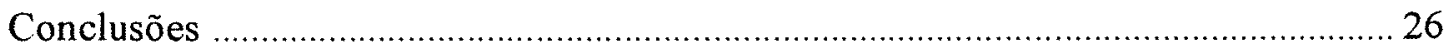

CAPÍTULO 3 - COMPOSIÇÃO CORPORAL E TAXAS DE DEPOSIÇÃO DOS

TECIDOS DE TOURINHOS DE DOIS GRUPOS GENÉTICOS ALIMENTADOS

COM DIETAS DE ALTO TEOR DE CONCENTRADO ……….............................. 27

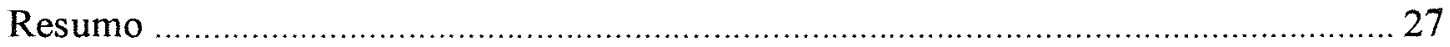

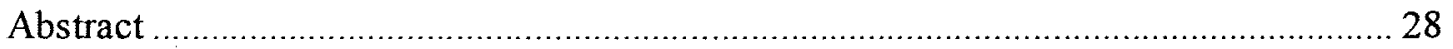

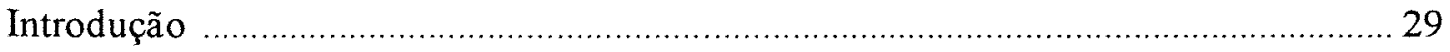

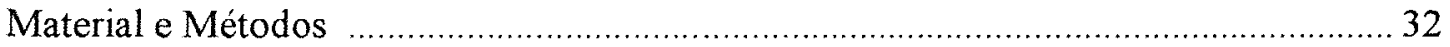

Resultados e Discussão

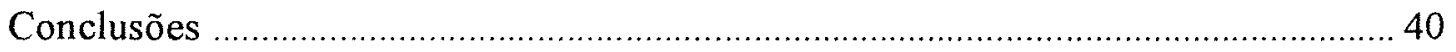

CAPÍTULO 4 - CONCLUSÕES FINAIS _...................................................................... 41

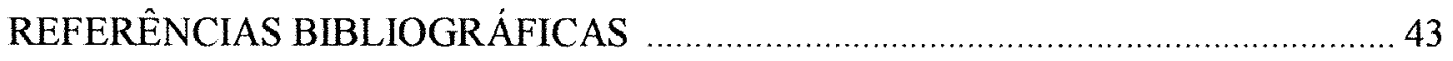




\title{
DESEMPENHO, COMPOSIÇÃO CORPORAL E EXIGÊNCIAS \\ LÍQUIDAS DE ENERGIA E PROTEÍNA DE TOURINHOS DE DOIS \\ TIPOS GENÉTICOS ALIMENTADOS COM DIETAS DE ALTO TEOR DE \\ CONCENTRADO.
}

\author{
Autora: MARIA LUISA DE MEDEIROS BULLE \\ Orientador: Prof. DANTE PAZZANESE D. LANNA
}

\section{RESUMO}

O objetivo deste trabalho foi avaliar o desempenho, a composição corporal e as exigências líquidas de energia e proteína de tourinhos de dois tipos genéticos, resultado do cruzamento de vacas Caracu x Nelore com pais Guelbvieh (raça Continental) ou com pais Shorthorn (raça Britânica). Também se avaliou o bagaço de cana in natura (BIN), como única fonte de fibra íntegra, em dietas de alta proporção de concentrado. Foram confinados durante 139 dias 36 tourinhos, 2 por baia, com dieta de alto teor de concentrado e níveis crescentes de bagaço in natura de 9\%,15\% e $21 \%$ da matéria seca. Outros seis animais similares foram abatidos após o periodo de adaptação para estimativa da composição corporal inicial. Não houve diferenças entre animais Britânicos e Continentais para ganho de peso vivo. Entre os três níveis de fibra, os animais que receberam $15 \%$ BIN apresentaram maior ganho de peso que os que receberam $9 \%$ BIN. O consumo foi o mesmo entre os dois grupos genéticos, mas animais que receberam dieta com $15 \%$ BIN apresentaram consumo superior ao $9 \%$ BIN. Não houve diferenças na eficiência de conversão alimentar entre os dois tipos genéticos e os três níveis de $\mathrm{BIN}$, sugerindo que dietas de alto concentrado e níveis de bagaço in natura de apenas $9 \%$ podem ser utilizadas. O peso da gordura renal e pélvica dos dois tipos 
genéticos não mostraram diferenças embora os animais Britânicos tenderam a apresentar maior quantidade de gordura. Entre os 3 niveis de fibra, animais que receberam $9 \%$ e $15 \%$ de BIN apresentaram maior acúmulo de gordura renal e pélvica de acordo com o fato de que estes animais receberam maior teor de energia na dieta. Os resultados de composição química do corte da 9-11 a costelas não demonstraram interação entre tipos genéticos e níveis de fibra, consistente com o fato de que todas as dietas são caracterizadas por alto nivel de concentrado e provavelmente função dos animais terem a mesma composição genética materna. Os animais de raça paterna Britânica apresentaram tendência a depositar mais gordura ( $8 \%$ a mais) que animais Continentais. O teor médio de lipídeo no ganho foi próximo a $28 \%$ e o teor de lipídeo ao abate foi de $18 \%$ aos $400 \mathrm{~kg}$ de peso vazio, sendo este último inferior a dados da literatura para touros Britânicos. As composições do corpo vazio e do ganho de corpo vazio de tourinhos $3 / 4$ Europeus filhos de vacas Caracu $x$ Nelore foram similares às observadas para animais Europeus de tamanho corporal grande ou de grau de estrutura corporal próximo a 8 na escala 1-9. Os diferentes niveis de BIN não alteraram a composição do ganho provavelmente porque todas as dietas apresentavam alto concentrado e da conseqüente pequena diferença no ganho de peso entre os tratamentos. Entretanto, animais recebendo dietas com $15 \%$ de BIN tenderam a uma maior taxa de ganho de peso vazio e a composição do ganho tendeu a conter maior porcentagem de extrato etéreo. A ausência de diferenças para efeito de tipos raciais para as características de desempenho, carcaça e composição é provavelmente, função de alguns fatores: a) pela diferença genética se limitar ao efeito paterno; b) baixo peso de abate; c) os animais serem inteiros; d) pelas características da raça Guelbvieh, que apresenta porte menor que a maioria das raças Continentais. Os resultados deste trabalho podem ser utilizados para parametrizar modelos de estimativa do desempenho e das exigências de animais $F_{2}$ resultantes do cruzamento com raças adaptadas às condições tropicais. Os resultados também demonstram que o BIN pode ser usado como único volumoso em dietas de alta proporção de concentrados. 


\title{
PERFORMANCE, BODY COMPOSITION AND NET ENERGY AND PROTEIN REQUERIMENTS OF BULLS OF TWO GENETIC GROUPS FED HIGH CONCENTRATE DIETS.
}

\author{
Author: MARIA LUISA DE MEDEIROS BULLE \\ Adviser: Prof. DANTE PAZZANESE D. LANNA
}

\section{SUMMARY}

The objective of this work was to evaluate the performance, body composition and net energy and protein requeriments of crossbreed bulls of two genetic groups. Caracu $\mathrm{x}$ Nelore cows were bred to Continental (Gelbvieh) or British (Shorthorn) sires and the calves taken to the feedlot after weaning. Sugar cane bagasse (BIN) was evaluated as the only source of fiber in high concentrate diets. The bulls were fed during 139 days, 2 per pen with a diet containing $9 \%, 15 \%$ e $21 \%$ of BIN in dry matter. Other 6 similar animals were slaughtered to obtain the initial body composition. There was no difference in shrink body weight gain between the two genetic groups. The $15 \%$ BIN treatment had a higher rate of gain than $9 \% \mathrm{BIN}$. The dry matter intake was the same between the two genetic groups, but the $15 \% \mathrm{BIN}$ animals had a higher dry matter intake than $9 \% \mathrm{BIN}$. There was no difference in the efficiency of feed conversion between the two genetic groups and among the three levels of BIN, suggesting that high concentrate diets with low levels $(9 \%)$ of BIN can be used. There was no difference between the two genetic groups in weight of kidney and pelvic fat (KPF) although British animals tended to have higher values. Among the three levels of fiber, $9 \%$ and $15 \%$ BIN treatments had higher KPF consistent with the higher energy content in the diet. The composition of the 9-11 th rib did not demonstrate interactions among genetic breed and level of BIN, consistent with the fact that all diets are characterised by a high proportion of concentrate and probably due to the fact that animals had the same maternal genetic composition. British 
animals tended to deposit more lipid (8\%) than Continental animals. The average lipid concentration in the gain was $28 \%$ and empty body lipid concentration at slaughter was $18 \%$ at $400 \mathrm{~kg}$ of empty body weight. These results indicate that they are leaner than results in the literature for British breeds. Composition of the empty body gain (net energy and protein requirements) of $3 / 4 B$. taurus $\mathrm{F}_{2}$ crossbreed bulls from Caracu $\mathrm{x}$ Nelore cows were consistent with NRC equation for large frame bulls or frame score 8 in a 1-9 scale. The different content of roughage in the diet did not change composition of gain, probably because all diets contained high proportion of concentrates and consequently little difference in empty body gain was observed among treatments. However, $15 \%$ BIN animals tended to show higher rate of empty body gain and body composition tended to have higher lipid content. Performance, carcass and body composition of the two genetic groups did not differ probably because a) differences were restricted to the paternal effects; b) the low weight at slaughter; c) intact males; $d$ ) and the fact that Gelbvieh animals have a smaller mature size than most Continental breeds. The results of this work can be used to parametrize computer models to estimate performance and requirements of animals adapted to tropical conditions. 


\section{Introdução}

Os dados existentes na literatura sobre as exigências nutricionais de mestiços zebuínos são escassos quando comparados com o grande volume de informações disponíveis para a estimativa das exigências nutricionais de taurinos (NRC, 1996). Assim, desde a década de 80 o grupo ESALQ/FZEA/Instituto de Zootecnia vem procurando preencher essa lacuna através de trabalhos desenvolvidos para estudar a composição corporal de bovinos zebuínos e determinação das exigências nutricionais e eficiência de crescimento. Os dados destes trabalhos (LEME et al., 1994; BOIN, 1995; LANNA et al., 1995; ALLEONI et al., 1997; HENRIQUE et al., 1999a; HENRIQUE et al., 1999b) tem sido utilizados para parametrizar modelos de simulação como o CNCPS (FOX et al., 1992; LANNA et al., 1997) e o RLM (LANNA et al., 1999).

Para avaliar o desempenho e exigências líquidas de zebuínos e seus cruzamentos em várias situações nutricionais, foram desenvolvidos experimentos com Nelore inteiros (LANNA, 1988; BOIN et al., 1995), castrados (LEME et al., 1994; ALLEONI et al., 1995), e novilhas (LANNA et al., 1998), novilhas Canchim (LANNA et al., 1998), machos inteiros Santa Gertrudis (LEME at al., 1997; HENRIQUE, et al., 1999 a; HENRIQUE, et al., 1999b; BERNDT et al., 1999), ganho compensatório de Nelore, Nelore x Marchigiana, cruzados leiteiros (LANNA, 1997). Mas o grupo não estudou os dados de animais cruzados F2, embora existam alguns dados na literatura nacional (FONTES, 1985). O objetivo deste estudo foi estudar o desempenho e composição de animais $\mathrm{F} 2$, resultado do cruzamento de vacas Caracu $\mathrm{x}$ Nelore com pais Guelbvieh (raça Continental), ou com pais Shorthorn (raça Britânica).

Juntamente com o estudo da composição corporal e taxas de deposição dos tecidos corporais, tratamentos nutricionais também foram avaliados. As dietas utilizadas, de alto teor de concentrado, permitem elevadas taxas de crescimento, influindo na proporção entre deposição de tecidos magros e tecidos gordurosos (FOX et al., 1992).

A utilização deste tipo de dieta pode proporcionar grandes beneficios, principalmente quando o custo de concentrados é baixo, além de maior velocidade e 
eficiência de crescimento animal, menor custo de mão-de-obra, menor necessidade de armazenamento de alimentos e geralmente maior uniformidade no desempenho. Em contrapartida, com o uso de dietas de alto concentrado são produzidos no rúmen grandes quantidades de ácidos, inclusive o ácido lático, que podem vir a causar problemas ruminais como acidose, paraqueratose, etc. Por este motivo, torna-se importante verificar o nível e a fonte de fibra íntegra quando grandes quantidades de grãos prontamente fermentecíveis são utilizadas.

O bagaço de cana in natura (BIN) que apresenta grande excedente no Brasil Central, tem sido pouco estudado, não se conhecendo seu nível ideal de utilização. $\mathrm{O}$ presente trabalho procurou avaliar a sua eficiência neste tipo de dieta, como única fonte de fibra íntegra, sendo ao mesmo tempo uma fonte de baixíssimo custo e facilmente disponivel em diversas regiões canavieiras. Devido a grande proporção de partículas de pequeno tamanho e a possibilidade de crescimento de fungos (BELTRAME FILHO, J.A, 1998), o BIN não se caracteriza como uma boa fonte de fibra íntegra, o que sugere a necessidade e importância determinar seu real potencial de utilização.

O objetivo deste estudo foi avaliar o desempenho, determinar a composição corporal e estimar a taxa de deposição de constituintes químicos de mestiços F2 Europeu x Zebuíno, utilizados nas condições de Brasil Central. Este estudo também procurou avaliar o BIN como único volumoso e identificar o nível ideal de utilização em dietas de alto teor de concentrado. 


\section{CAPÍtulo 1 \\ REVISÃO DE LITERATURA}

\section{Tipos Genéticos, Exigências Nutricionais, Composição Corporal}

Para BRODY (1968), o crescimento é a síntese biológica cujo produto são novas unidades bioquímicas. É possível encontrar sintese de novas unidades bioquimicas sem haver acúmulo do peso total, de algum tecido ou componente químico corporal, dada a existência de um processo catabólico simultâneo. Utilizando o conceito de crescimento como o resultado líquido de acúmulo de novas unidades bioquimicas, é interessante estudar e avaliar o crescimento definindo as unidades bioquímicas depositadas.

A determinação das curvas de crescimento dos componentes químicos corporais em função do peso animal permite avaliar os tratamentos nutricionais possibilitando a determinação da eficiência energética e protéica do crescimento, permitindo a determinação dos requerimentos líquidos de energia, proteína, minerais e, também, uma avaliação mais precisa do valor nutricional dos alimentos (LANNA, 1988).

As exigências líquidas de energia, proteína e minerais são iguais às taxas de deposição destes ao longo do crescimento do animal. Ou seja, a exigência líquida é equivalente à composição dos tecidos depositados.

Embora o Brasil possua o maior rebanho comercial bovino do mundo, há uma notável falta de informações sobre as exigências nutricionais dos tipos genéticos usados nas nossas condições. Diversos trabalhos vem sendo conduzidos por diversos grupos de pesquisa com o objetivo de gerar estes dados de exigências, incluíndo trabalhos feitos pelo grupo da ESALQ/FZEA/IZ citados em BOIN (1995) e LANNA et al., (1999). Dados de exigências líquidas permitem a construção de modelos matemáticos para estimativa das exigências dietéticas de bovinos de corte $\mathrm{e}$ estimativa do desempenho e eficiência de crescimento. 
A determinação da composição corporal de bovinos é trabalhosa e cara, mas é de grande importância em estudos de nutrição que avaliam alimentos ou o crescimento em si. A determinação direta da composição é inviável como rotina experimental. Mas com o esforço de vários pesquisadores, diversas metodologias foram desenvolvidas e assim tem sido possivel identificar alterações na composição corporal em função da raça, sexo e composição da dieta entre outros tratamentos que alteram a composição do crescimento.

Muitos pesquisadores tem desenvolvido métodos indiretos que possam estimar com boa precisão a composição corporal. Dentre esses métodos, a composição fisica do corte da $9-11^{a}$ costelas tem estimado com precisão a composição da carcaça de bovinos (HANKINS \& HOWE, 1946). Resultados semelhantes tem sido obtidos com a composição química desse mesmo corte em zebuínos para os quais equações específicas foram desenvolvidas (ALLEONI, 1995; LANNA et al., 1995).

LANNA (1988), afirma que a utilização de métodos que não utilizem o abate do animal podem ser repetidos várias vezes no mesmo animal, podem reduzir a mão de obra, o número de animais e os custos com a depreciação da carcaça, porém essas medidas obtidas no animal vivo, não apresentam uma boa acurácia o que inviabiliza a sua utilização.

LUSH (1926) concluiu que o corte da costela era aquele que melhor representava a composição da carcaça. $O$ autor enfatizava a importância de não se determinar apenas a composição da carcaça, mas de todo o corpo vazio, para que os resultados fossem de maior utilidade em experimentos de nutrição animal.

Após os trabalhos de LUSH (1926) técnicos do USDA propuseram a utilização não mais de todo o corte da costela, mas apenas o corte da $9-11^{\text {a }}$ costelas. O uso desta técnica, resultaria em maior precisão das estimativas e menor depreciação da carcaça.

HOPPER (1944) mostrou que a utilização do corte da $9-11^{a}$ costelas produzia regressões com menores quadrados médios do resíduo do que as regressões que se utilizavam da composição de todo o corte da costela. Estas regressões foram feitas sempre em porcentagem do componente no corte e na carcaça ou no corpo vazio. 
VANCE et al (1971) regrediram a composição da parte comestivel da carcaça em relação à composição de todo o corte das costelas, separado pelo sistema inglês. O coeficiente de determinação para estimativa da porcentagem de gordura na carcaça foi de 0,656. Esse resultado, obtido com animais muito semelhantes aos utilizados por HOPPER (1944) e por HANKINS e HOWE (1946) parece demonstrar que a proposição de se utilizar a seç̧ão da $9-11^{\text {a }}$ costelas é correta, já que os coeficientes de determinação encontrados quando o corte da $9-11^{a}$ costelas foi utilizado como variável explicativa são superiores, ao redor de 0,90 .

Em trabalho clássico, REID et al (1955) reviu um grande número de dados publicados no início do século por pesquisadores americanos, concluindo e propondo que a composição corporal poderia ser estimada com grande precisão a partir do conhecimento da quantidade de água ou de gordura no corpo animal e que esta guardava uma relação muito próxima com o peso vazio. $\mathrm{O}$ desenvolvimento da técnica do corte da 9-11 a costelas por HOPPER (1944) e HANKINS E HOWE (1946) foi importante, pois KEMPSTER et al (1982), já indicavam que o peso vivo é um bom indicador da composição corporal apenas quando comparamos animais de mesma raça, mesmo sexo e criados em um mesmo sistema de produção. Outros fatores como manejo da alimentação, tratamentos hormonais, doenças, enchimento do trato gastro-intestinal e variações individuais, limitam o uso do peso como único indicador da composição. Portanto a técnica da $9-11^{\text {a }}$ costelas tem sido importante no desenvolvimento de estudos da composição corporal e das exigências líquidas de energia, proteína e macro- elementos minerais.

Os trabalhos de LANNA (1988) e ALLEONI et al (1997) demonstram que há necessidade do estabelecimento de equações específicas para cada grupamento genético estudado.

Assim, essas equações tem sido validadas tanto no Brasil como no exterior para diferentes grupamentos genéticos. HENRIQUE et al (1999b) desenvolveram equações para estimativa da composição química corporal de bovinos de bovinos Santa Gertrudis a partir da composição do corte da $9^{\mathrm{a}}-11^{\mathrm{a}}$ costelas. As porcentagens de água e gordura da $9^{\mathrm{a}}-11^{\mathrm{a}}$ costelas mostraram-se altamente correlacionadas com a composição química corporal. 
Em resumo, é extremamente importante obter a composição do crescimento em estudos que avaliem grupos genéticos ou tratamentos nutricionais e hormonais. A composição do corte das costelas tem se demonstrado uma técnica consistente, mas que requer equações específicas para diferentes grupos genéticos. Os dados gerados podem ser utilizados em modelos matemáticos de simulação para estimativa das exigências e desempenho como o CNCPS (FOX et al., 1992; LANNA et al., 1998) e RLM (LANNA et al., 1999). 


\section{Dietas de Alto Teor de Concentrado}

Em sistemas intensivos de produção de gado de corte, o uso de dietas de alto teor de concentrado apresenta vantagens como maior velocidade e eficiência de crescimento animal, menores custos com mão-de-obra e armazenamento e maior uniformidade no desempenho.

BELTRAME FILHO et al (1998), simulou a viabilidade econômica do aumento dos níveis de concentrado para diferentes regiões brasileiras utilizando preços médios de alimentos e arroba bovina entre 1994 e 1996. Para o Estado de São Paulo, as dietas de lucro máximo apresentavam níveis de volumosos próximos a $40 \%$ da MS, sendo importante portanto a produção de volumoso de alta qualidade e baixo custo. Estados como o Paraná e Mato Grosso onde o preço do concentrado é mais baixo, a simulação demonstrou ser interessante incluir até $78 \%$ de concentrado na matéria seca da dieta.

Um cuidado importante a ser tomado é o de que cada genótipo parece possuir exigências mínimas de volumosos específicas. Embora não tenham sido conduzidas pesquisas metódicas capazes de definir estas exigências, sabe-se que quanto maior a proporção de sangue zebuíno, maior a possibilidade da ocorrência de distúrbios metabólicos como acidose, laminite e paraqueratose. Raramente se tem conseguido valores de NDT superiores a $68 \%$ em animais com $100 \%$ de sangte zebuíno, mesmo em dietas com mais de $65 \%$ da matéria seca de concentrado (LANNA, 1998). Em diversas situações, zebuínos não atingem elevados desempenhos com dietas de alta proporção de concentrado e diversos autores apontam problemas a nível de rúmen e/ou intestino.

Para que dietas de alto concentrado tenham sua utilização otimizada, se faz necessário adaptação dos microorganismos ruminais gradativamente à utilização dos carboidratos prontamente fermentecíveis. Quando se realiza uma troca repentina da dieta, passando de uma base de volumosos fibrosos (forragens) para uma dieta com alto concentrado, podem ocorrer problemas de ordem digestiva como o aumento na produção de ácidos, principalmente láctico, acompanhados por uma diminuição no consumo, baixos ganhos no peso vivo, prejuízos nas paredes do retículo e do rúmen, diminuição da função hepática e aparecimento de abscessos no figado (PRESTON, 
1998). Dessa forma, é necessário um processo de adaptação, onde seriam fornecidas ao longo de 2 a 4 semanas, niveis decrescentes de volumosos para a adaptação dos microorganismos do rúmen (PRESTON, 1998).

Os bovinos tem sido adaptados de dietas a base de forragens para dietas a base de grãos num período de duas a quatro semanas passando por quatro níveis de volumoso $(50 \%, 30 \%, 20 \%, 10 \%)$. E necessário um período de adaptação para os microorganismos do rúmen. Inicialmente, ocorre uma rápida fermentação de amido com formação principalmente de ácido propiônico e láctico, mas, pode ocorrer um excesso desse último ácido no rúmen (PRESTON, 1998). KUNKLE et al.(1976), estudando a adaptação in vitro e in vivo descobriu que a taxa de desaparecimento do ácido láctico ocorria mais devagar quando era oferecido feno comparado com feno com ácido láctico ou uma dieta a base de concentrado. Pesquisas posteriores mostraram uma relação positiva entre os niveis de grãos da dieta e o desaparecimento de ácido láctico in vitro, aumentando entre 25 e $55 \%$ de grãos, mudando minimamente entre 60 e $80 \%$ de grãos, e aumentando substancialmente com $95 \%$ de grãos (BYERS \& GOODALL, 1979). Esses resultados sugerem que rápidos aumentos dos níveis de grãos na dieta podem ser feitos de zero a $55 \%$ de concentrado, entre 55 a $80 \%$ de concentrado os aumentos devem ser mais lentos, e finalmente após $80 \%$, mudanças rápidas podem ser feitas até o nível final de concentrado.

Grandes oscilações no consumo podem ocorrer quando se aumenta o concentrado e diminui o volumoso. Tais variações são particularmente problemáticas nestas condições pois podem precipitar a ocorrência de distúrbios nutricionais. Várias maneiras têm sido usadas para minimizar esse problema, incluindo aumento limitado da dieta usando-se um horário pré determinado que pode ser ajustado dependendo do tipo e histórico dos animais. Esses métodos ajudam a melhorar o manejo, mas não previnem o aparecimento da acidose. PRESTON, (1998) descreve um sistema chamado "consumo máximo limitado" em que o consumo durante as primeiras semanas aumenta seguido por uma redução na terceira e quarta semanas. XIONG et al. (1991) usaram esse enfoque para iniciar vários grupos de bovinos. O consumo ad libitum foi comparado com limites de 2.3, 2.5, 2.7 e 2.9 vezes suas necessidades em energia líquida de mantença (baseados no peso ao início de cada 
período de 28 dias). Não houve diferença entre os animais alimentados ad libitum e aqueles alimentados no sistema de consumo máximo limitado. BARTLE e PRESTON (1992) compararam três regimes alimentares ad libitum; 2.3, 2.5, 2.7, 2.9, e $2.1,2.3,2.5,2.7$ vezes seu requerimento de energia líquida durante a primeira, segunda, terceira e quarta semana respectivamente. O período total de alimentação foi de 116 dias e foi oferecido uma dieta de alto nível de concentrado. Apesar de não ter apresentado diferenças significativas, houve uma tendência de melhora no ganho e eficiência para os animais alimentados com o consumo máximo limitado. O ganho e eficiência foram melhorados 7 e $4 \%$ com o regime de maior restrição comparado com o regime ad libitum. Durante os primeiros 28 dias, a porcentagem de restrição nos dois tratamentos com consumo máximo limitado foi de : 46,83,63, e 17\%; e, 57, $86,71,37 \%$, respectivamente.

BARTLE e PRESTON (1992), BARTLE e PRESTON (1991) e BARTLE et al (1994) compararam desempenho, características de carcaça de animais alimentados com um nível constante de volumoso $(10 \%)$ por todo o período de alimentação; animais alimentados com baixo nível de volumoso $(2 \%)$ durante metade do período de alimentação (22-84 dias) e depois aumentando o nível até 10\% de volumoso pelo restante do período. Durante o período com $2 \%$ de volumoso, o consumo foi menor $(\mathrm{P}<.01)$ devido a maior densidade energética, o ganho foi menor provavelmente devido ao menor enchimento e a eficiência alimentar foi melhorada em $6 \%$. Após o aumento da porcentagem de volumoso da dieta para $10 \%$, o consumo aumentou, ganharam peso mais rápido e foram mais eficientes. Durante todo o período de alimentação, os animais alimentados com restrição de volumoso comeram menos, tiveram o mesmo ganho, tendendo a ser mais eficientes e os custos com alimentação foram reduzidos.

$O$ teor de energia da dieta influencia a composição do ganho de peso. REID et al (1968), propuseram que para um determinado grupo genético, a composição do crescimento é fundamentalmente função do peso vazio e pouco influenciada pela composição da dieta. Posteriormente, estudos conduzidos pelo próprio Reid (SIMPFENDORFER, 1974; ANRIQUE, 1976; FORTIN, 1980) demonstraram que dietas com altas proporções de grãos alteravam a composição corporal, aumentando a proporção de gordura no ganho. Este efeito foi confirmado por inúmeros 
experimentos conduzidos subsequentemente. $\mathrm{O}$ efeito do teor de energia da dieta na composição do ganho está incluído em diversos sistemas de alimentação (NRC, 1996).

BYERS (1980) sugere que o teor de energia na dieta que altera a composição do ganho é função do potencial genético do animal para depositar proteína. Em animais Britânicos, sugere que quando os animais ganham peso em taxas acima de 900 gramas por dia há um aumento na proporção de gordura no crescimento depositado. Um dos objetivos deste trabalho foi obter mais dados avaliando o efeito do teor de energia da dieta sobre a composição do ganho de peso de bovinos cruzados B. taurus $\mathrm{x}$ B. indicus usados nas condições de Brasil Central. 


\section{Bagaço de Cana-de-Açúcar in natura}

O bagaço de cana in natura (BIN) é o maior resíduo da agroindústria brasileira e se constituiu num problema para a indústria sucro alcooleira devido ao grande excedente acumulado no pátio das indústrias, visto que cada tonelada de cana moida produz cerca de $250-300 \mathrm{~kg}$ de bagaço e que de parte deste material não é utilizado no processo de geração de energia dentro da usina. A produção de cana-deaçúcar em 1999, no Estado de São Paulo foi de 193 milhões de toneladas. (Instituto de Economia Agrícola e Coordenadoria e Assistência Técnica Integral, 1999).

De $75 \%$ a $100 \%$ desse bagaço, é usado nas próprias usinas como fonte energética, porém até $25 \%$ desse material podem ser usados para outros fins, tais como nutrição de ruminantes, principalmente por ser rico em parede celular (PRESTON, 1995), e ser um produto muito barato em relação a outros volumosos mais comumente utilizados em dietas de confinamento (FNP/BOVIPLAN, 1997).

O Bagaço de cana-de-acúçar in natura é um alimento rico em constituintes de parede celular, de baixo teor de conteúdo celular, baixa digestibilidade, baixa densidade e pobre em proteinas e minerais (CASTRO, 1989). Sua baixa densidade, aliado a um reduzido valor comercial limitam seu transporte a longas distâncias. Existem várias possibilidades de uso do bagaço, dentre as principais estão a geração de energia e a alimentação animal.

Alguns trabalhos de pesquisa exploram a utilização do BIN na alimentação de ruminantes. EZEQUIEL et al (1988) estudando o uso de BIN sobre a ingestão e disponibilidade da dieta em comparação com a palha de arroz, feno de grama estrela e de capim colonião, mostraram que o consumo e a digestibilidade de MS e FB foram menores nas dietas contendo BIN.

THIAGO et al (1983) estudando a substituição de BIN em dietas para novilhos em engorda, demonstram que a inclusão de BIN em niveis superiores a $40 \%$ da MS em substituição a ponta de cana prejudicaram o desempenho dos animais, sugerindo como máximo $20 \%$ da MS. Esses resultados estão de acordo com os de PACOLA et al (1984) onde, assumindo níveis superiores a $30 \%$ na MS, o BIN reduziu o consumo de MS e o ganho de peso de bovinos em confinamento. Trabalhando com bovinos confinados, PACOLA et al (1977) forneceram ração 
completa com $40 \%$ de BIN na MS, o que prejudicou o consumo e proporcionou ganhos de apenas 650-720 g/cabeça/dia. A mesma tendência de redução de consumo foi verificada por BURGI (1985), com a adição de $60 \%$ de BIN na MS de dietas de bovinos de corte confinados, obtendo consumo de $1,91 \%$ do PV.

Nos trabalhos acima o BIN foi avaliado como volumoso da forma tradicional, na maioria das vezes em dietas mistas. BELTRAME FILHO (1998) analisou o BIN como única fonte de volumoso, comparado-o à silagem de milho, em dietas de alto teor de concentrado. O tipo de volumoso apresentou efeito sobre o desempenho sendo o ganho de peso e a conversão bastante superiores nas dietas de silagem de milho em relação ao BIN. Entretanto o consumo de matéria seca em relação ao peso vivo não apresentou diferenças entre os tratamentos. Neste experimento, usando $12 \%$ de BIN na MS da dieta, o autor não observou problemas como laminite ou acidose clínica nos animais alimentados com BIN.

No Brasil, o uso do BIN para alimentação animal tem sido feito após tratamentos para aumentar o seu valor nutritivo. Estes tratamentos incluem o tratamento a pressão e vapor (BTPV) e com uso de $\mathrm{NaOH}$.

O bagaço de cana tratado sob pressão e vapor recebe um tratamento físicoquímico que resulta em aumento da concentração de carboidratos solúveis e da digestibilidade potencial da FDN.

$\mathrm{O}$ tratamento sob pressão e vapor visa romper as ligações entre a lignina e os carboidratos complexos constituintes da parede celular tornando-os mais susceptiveis aos ataques das enzimas dos microorganismos celulolíticos do ecossistema ruminal. Segundo TAYLOR \& ELSDALE (1980), esse processo é o resultado da permanência de material ligno-celulósico a elevadas temperaturas e pressão, ocorrendo a liberação de ácidos orgânicos que degradam o complexo lignocelulósico. Além da produção de ácidos orgânicos existe também a produção de outros ácidos, compostos fenólicos e perda de matéria seca que pode variar de 1 a 20\% (WALKER,1984). A exigência de proteína metabolizável (amino-ácidos absorvidos no intestino) em dietas com BTPV podem ser alteradas pelos compostos fenólicos produzidos durante a hidrólise já que estes compostos inibem a digestão e absorção da proteína no intestino. 
Outra alteração que ocorre com o tratamento é devido à repentina descompressão ao final do processo que reduz o tamanho das partículas. Esta redução do tamanho tem profundas implicações para a dinâmica da digestão do BTPV, pois reduz o teor de FDN efetivo com consequente redução do efeito de fibra integra. A diminuição da granulometria do $\mathrm{BAH}$ durante o tratamento afeta o trânsito deste pelo trato digestivo, e também inibe a formação no rúmen de um emaranhado de fibras característico das dietas que apresentam fibra longa. A falta desta camada no rúmen, responsável pela retenção de partículas pequenas de baixa digestibilidade, leva as partículas sólidas a deixar o rúmen mais rapidamente, sendo menos digeridas (VAN SOEST, 1994). CASTRO (1989) determinou o tempo de retenção do BIN no rúmen como sendo igual a $47,32 \mathrm{~h}$ e o do BTPV, 33,46 h. A extensão de degradação de um alimento é função de sua taxa de degradação combinada com sua taxa de passagem. No caso do BTPV, as condições ruminais inadequadas determinam baixa taxa de degradação e a taxa de passagem é alta, resultando em baixa degradação desse alimento no rúmen (CASTRO, 1989). Altas taxas de passagem em dietas mistas com mais de $40 \%$ de concentrado na MS da dieta podem resultar em diminuição na digestibilidade tanto da fibra como do amido. Aparentemente isso ocorreu no experimento de MEDEIROS (1992). Estas alterações nas taxas de passagem seriam responsáveis pelas altas ingestões observadas em dietas com alta proporção de BTPV. Nestas dietas a ingestão voluntária é cerca de $15 \%$ superior à estimada pelo NRC (NRC, 1996) em função dessas alterações na gravidade específica, tamanho de partícula e taxa de degradação no rúmen.

Em dietas de alta proporção de concentrado, o tratamento com pressão e vapor, bem como o tratamento com $\mathrm{NaOH}$ não seriam indicados. Isto porque o aumento da digestibilidade do bagaço obtido com estes tratamentos é grandemente reduzido quando a dieta contém altas proporções de concentrado e o meio ruminal não é adequado para maximizar a digestão de fibras. Em segundo lugar, como já discutido acima, o tratamento de hidrólise sob pressão reduz a efetividade da fibra. Em função do exposto é importante definir o potencial do BIN em dietas de alta proporção de concentrado, encontrando o teor mais adequado de adição, além da comparação com outros volumosos padrões como realizado no trabalho de BELTRAME FILHO (1998). 


\section{CAPÍtULO 2 \\ BAGAÇO DE CANA-DE-AÇÚCAR COMO ÚNICO VOLUMOSO EM DIETAS DE ALTO TEOR DE CONCENTRADO. 1.DESEMPENHO.}

RESUMO: O objetivo deste trabalho foi avaliar o desempenho de tourinhos $3 / 4$ Europeu $1 / 4$ Zebu, de raça paterna Britânica ou Continental em dietas de alto teor de concentrado contendo 9, 15 e $21 \%$ da matéria seca (MS) de bagaço de cana- deaçúcar in natura (BIN) em arranjo fatorial $2 \times 3$. Trinta e seis tourinhos com idade média de 9 meses e peso vivo inicial de $257 \mathrm{~kg}$ foram confinados 2 por baia por 139 dias. Não houve interação entre os tratamentos para nenhuma variável. Entre os dois tipos genéticos não houve diferenças em ganho de peso vivo em jejum (PVj), os Britânicos ganhando $1,24 \mathrm{~kg} / \mathrm{d}$ e os Continentais, $1,29 \mathrm{~kg} / \mathrm{d}$ e a eficiência de conversão de alimentos foi a mesma 0,17 . O tratamento com $15 \%$ de BIN apresentou ganho de peso maior $(1,36 \mathrm{~kg} / \mathrm{d})$ que o tratamento $9 \%(1,20 \mathrm{~kg} / \mathrm{d})$ sendo o tratamento $21 \%$ intermediário $(1,24 \mathrm{~kg} / \mathrm{d})$. O peso final dos animais Britânicos $(428,1 \mathrm{~kg})$ não diferiu dos Continentais $(438,4 \mathrm{~kg}$ ), assim como o consumo de MS (respectivamente 7,20 e $7,54 \mathrm{~kg} / \mathrm{d}$ ) e o consumo em \% do PVj foram iguais (respectivamente $2,11 \mathrm{e}$ $2,16)$. Entre os três niveis de fibra analisados, o maior peso final foi do tratamento $15 \% \mathrm{BIN} ; 448,7 \mathrm{~kg}$ e o menor o tratamento $21 \% \mathrm{BIN} ; 424,8 \mathrm{~kg}$ sendo o tratamento $9 \% \mathrm{BIN}$ intermediário; $426,8 \mathrm{~kg}$. O maior consumo de MS foi apresentado pelo tratamento $15 \% \mathrm{BIN}$, o menor consumo foi o $9 \% \mathrm{BIN}$. Estes resultados sugerem que dietas de alto concentrado com BIN como única fonte de fibra podem ser utilizados em níveis tão baixos como $9 \%$ da MS. O desempenho dos dois tipos genéticos não diferiu talvez devido ao baixo peso de abate, ao efeito apenas das raças paternas e o fato da raça Guelbvieh não ter características de raça de grande porte como outras raças Continentais.

Palavras Chaves: bagaço de cana, bovinos, concentrado, confinamento, tourinhos, volumoso 


\title{
SUGAR CANE BAGASSE IN HIGH CONCENTRATE DIETS FOR BULLS. i. PERFORMANCE
}

\begin{abstract}
The objective of this work was to evaluate the performance of $3 / 4$ European $x{ }^{1 / 4}$ Zebu crossbred bulls with British or Continental paternal breed, on high concentrate diets containing 9,15 or $21 \%$ of dry matter (DM) of sugar cane bagasse (BIN) in a $2 \times 3$ factorial arrangement. Thirty-six crossbred bulls, 9 months old and $257 \mathrm{~kg}$ of shrink body weight were fed, two per pen, for 139 days. There was no difference in shrink body weight gain between the two genetic groups, the British animals gaining $1,24 \mathrm{~kg} / \mathrm{d}$ and the Continentals $1,29 \mathrm{~kg} / \mathrm{d}$. The efficiency of feed conversion was also the same 0,17 . The $15 \%$ BIN animals had a higher rate of gain $(1,36 \mathrm{~kg} / \mathrm{d})$ than $9 \% \mathrm{BIN}(1,20 \mathrm{~kg} / \mathrm{d})$; with $21 \% \mathrm{BIN}$ bulls having intermediate gains $(1,24 \mathrm{~kg} / \mathrm{d})$. The final weight of the British animals $(428,1 \mathrm{~kg})$ did not differ to the Continental bulls $(438,4 \mathrm{~kg})$ as well as the dry matter intake (respectively 7,$20 ; 7,54$ $\mathrm{kg} / \mathrm{d}$ ). Of the three roughage levels, the highest final weight was for the $15 \% \mathrm{BIN}$ treatment; $448,7 \mathrm{~kg}$, the lowest for the $21 \% \mathrm{BIN} ; 424,8 \mathrm{~kg}$ and intermediate for the $9 \% \mathrm{BIN}$ treatment, $426,8 \mathrm{~kg}$. The highest dry matter intake was for the $15 \% \mathrm{BIN}$ $(7,93 \mathrm{~kg} \mathrm{DM} / \mathrm{d})$ and the lowest for the $9 \%$ BIN treatment $(6,85 \mathrm{~kg} \mathrm{DM} / \mathrm{d})$. These results suggest that high concentrate diets with very low level of BIN can be used. The performance of the two genetic groups did not differ probably due to the low weight of slaughter, to the genetic effects only through the paternal breed and the fact that the Guelbvieh breed have characteristics different from the large mature size Continental breeds.
\end{abstract}

Key Words: bulls, feedlot, fiber, high concentrate, sugarcane bagasse, roughage 


\section{Introdução}

Avaliações de diferentes grupos genéticos quanto ao desempenho, composição corporal e exigências nutricionais são fundamentais para a elaboração de padrões de alimentação e modelos de computador que auxiliem produtores e extensionistas a conduzirem programas nutricionais. Diversos trabalhos vem sendo conduzidos em um amplo estudo da composição corporal de bovinos para estimar suas exigências nutricionais e eficiência de crescimento (LEME et al., 1994; BOIN, 1995; LANNA et al., 1995; LANNA et al., 1998; LEME et al., 1999). Os dados destes trabalhos tem sido utilizados para parametrizar modelos de simulação como o CNCPS (FOX et al., 1992; LANNA et al., 1996; LANNA et al., 1997) e o RLM (LANNA et al., 1999). Trabalhos na mesma linha tem sido desenvolvidos por outros grupos (LANA et al., 1992; FONTES, et al., 1995). Embora um número razoável de informações de desempenho e exigências nutricionais tenham sido feitas com bovinos Nelore, Canchim, Santa Gertrudis, e Cruzados $F_{1}$, existem relativamente poucos dados de animais cruzados $F_{2}$. Neste trabalho, foram utilizados animais filhos de vacas Caracu $\mathrm{x}$ Nelore com pais de raças Continentais e Britânicas, mais especificamente Guelbvieh e Shorthorn.

Além do estudo da composição corporal e taxas de deposição dos tecidos corporais, os tratamentos nutricionais em dietas de alto concentrado são também alvo de atenção.

$\mathrm{O}$ uso de dietas de alto teor de concentrados fornecidas ad libitum é prática comum na indústria de gado de corte norte-americana (PRESTON, 1998). Essa prática caracteriza-se por rápido ganho de peso, alta eficiência de conversão alimentar e conseqüente diminuição no tempo de terminação para abate, menor custo de mão-de-obra, menor necessidade de armazenamento de alimentos e geralmente maior uniformidade no desempenho. WOODY et al (1983) estudando o efeito de níveis de grãos nas dietas de bovinos em acabamento, encontraram que animais alimentados com dietas de alto concentrado com $90 \%$ de grãos ganharam $7 \%$ mais rápido e apresentaram requerimento alimentar $16 \%$ menor por unidade de ganho do que animais alimentados com $70 \%$ de grãos. 
Entretanto, esta prática pode ocasionar problemas de ordem digestiva acompanhados de diminuição no consumo, baixo ganho de peso, prejuízo à parede do rúmen e aparecimento de abscessos no figado (PRESTON,1998). Isso ocorre quando ruminantes ingerem grandes quantidades de carboidratos prontamente fermentecíveis típico de dietas de alto concentrado, onde a acidificação e a osmolaridade ruminal aumentam conforme os ácidos se acumulam. Sinais clínicos como pH ruminal, anorexia, consumo variável, diarréia e letargia, são indicativos de quadro acidótico que pode ter manifestação sub-clínica (OWENS et al., 1998). FULTON et al (1979) observaram que seguindo um turno de acidose, o consumo diminui, sugerindo que um padrão de consumo cíclico reflete turnos de acidose. A taxa de degradação de amido varia com a fonte de grão, processamento e tipo de amido. Em certas variedades de grãos o amido é hidrolizado mais ra $a_{\mathfrak{1}}$ thamente do que outras fontes ou variedades da mesma espécie. Grãos de amido envoltos em proteína no endosperma por exemplo, tem menor superficie exposta ao ataque microbiano. A redução do tamanho de partícula, tratamento com pressão e calor e ensilagem em alta umidade aumenta a disponibilidade do amido e a propensão à acidose. Para prevenir acidose é preferivel taxas de fermentação mais lentas (OWENS et al., 1998).

Para melhorar essas condições, o tipo de volumoso e o nivel de inclusão na dieta são de grande importância para o sucesso neste tipo de sistema.

No Brasil, as dietas para confinamento tem sido tradicionalmente balanceadas com altas proporções de volumosos. Em anos de preços vantajosos de concentrados, dietas de alto concentrado tem se tornado viáveis economicamente já que o ganho de peso é mais rápido, havendo redução nos custos de mão de obra, tornando a atividade mais rentável. Neste tipo de dieta a fonte de volumoso entra apenas com a função de estimular a ruminação e salivação, bem como formar um "tapete" de fibras no rúmen, aumentando o tempo de permanência do alimento. Este efeito é obtido pela chamada fibra íntegra.

BELTRAME FILHO (1998), estudando o efeito do bagaço in natura e silagem de milho como fonte de fibra íntegra em dietas de alto concentrado para novilhos em terminação concluiu que o bagaço pode ser utilizado como fonte exclusiva de volumoso, embora o ganho de peso e eficiência de conversão tenham sido inferiores 
aos observados com silagem de milho, comparados à mesma proporção de concentrado ( $88 \%$ da matéria seca).

Os objetivos do presente trabalho foram: 1) avaliar o desempenho de cruzamentos de bovinos de corte com $75 \%$ de sangue Europeu, 25\% de Zebu e 50\% de animais adaptados ao Brasil Central; 2) procurar identificar o nível ideal de uso do bagaço in natura de cana-de-açúcar como única fonte de fibra em dietas de alto concentrado.

\section{Material e Métodos}

Foram confinados em 18 baias parcialmente cobertas, 2 animais por baia, 36 tourinhos cruzados ( $3 / 4$ de sangue Europeu, $1 / 4$ sangue Zebu), com idade média de 9 meses e peso em jejum médio de $257 \mathrm{~kg}$ ao início do período experimental. Os animais eram filhos de vacas Caracu $\mathrm{x}$ Nelore, sendo a raça paternal Britânica (Shorthorn) ou Continental (Gelbvieh).

Os animais foram distribuídos aleatoriamente às baias e receberam durante 42 dias de adaptação dieta com níveis crescentes de concentrado até atingir $21 \%$ de bagaço in natura. Outros 6 animais similares foram abatidos após este período para determinação da composição química corporal inicial do lote.

$\mathrm{O}$ volumoso utilizado durante o experimento foi o bagaço in natura, e o concentrado composto de farelo de soja, soja extrusada, milho, e polpa de citrus.

As dietas testadas continham 3 níveis de bagaço de cana-de-açúcar in natura (BIN), de 9, 15 e $21 \%$ da matéria seca total da dieta e foram balanceadas de acordo com o Cornell Net Carbohydrate and Protein System - CNCPS (FOX et al., 1992), para atender as exigências estimadas de proteína degradável no rúmen e proteína metabolizável para o animal, bem como as exigências de peptídeos das bactérias do rúmen (Tabela 1). 
Tabela 1. Composição das dietas experimentais (\% na matéria seca)

Table 1. Composition of the experimental diets (\% in dry matter)

\begin{tabular}{|c|c|c|c|}
\hline \multirow{2}{*}{$\begin{array}{l}\text { INGREDIENTES } \\
\text { Ingredients }\end{array}$} & \multicolumn{3}{|c|}{$\begin{array}{l}\text { NIVEL DE BAGAÇO IN NATURA, } \\
\text { Level of Sugarcane Bagasse in natura }\end{array}$} \\
\hline & $9 \% \mathrm{BIN}$ & $15 \% \mathrm{BIN}$ & $21 \% \mathrm{BIN}$ \\
\hline Bagaço de cana & 9,0 & 15,0 & 21,0 \\
\hline \multicolumn{4}{|l|}{ Sugarcane Bagasse } \\
\hline Farelo de soja & 8,5 & 9,6 & 10,3 \\
\hline \multicolumn{4}{|l|}{ Soybean meal } \\
\hline Soja extrusada & 4,5 & 4,5 & 4,5 \\
\hline \multicolumn{4}{|l|}{ Extruded soybean meal } \\
\hline Milho moído & 45,1 & 40,9 & 37,1 \\
\hline \multicolumn{4}{|l|}{ Grounded corn } \\
\hline Polpa cítrica & 31,0 & 27,9 & 25,1 \\
\hline \multicolumn{4}{|l|}{ Citrus pulp } \\
\hline Cloreto de potássio & 0,1 & 0,1 & 0,1 \\
\hline \multicolumn{4}{|l|}{ Potassium chloride } \\
\hline Sal mineralizado & 0,8 & 0,8 & 0,8 \\
\hline \multicolumn{4}{|l|}{ Mineral salt } \\
\hline Rumensin & 0,03 & 0,03 & 0,03 \\
\hline \multicolumn{4}{|l|}{ Rumensin } \\
\hline Uréia & 1,0 & 1,0 & 1,0 \\
\hline \multicolumn{4}{|l|}{ Urea } \\
\hline \multicolumn{4}{|l|}{ NUTRIENTES } \\
\hline \multicolumn{4}{|l|}{ Nutrients } \\
\hline Proteina bruta, \% & 14,6 & 14,6 & 14,5 \\
\hline \multicolumn{4}{|l|}{ Crude protein,\% } \\
\hline NDT, $\%^{1}$ & 78,8 & 75,4 & 72,0 \\
\hline
\end{tabular}

\footnotetext{
${ }^{1}$ Nutrientes digestíveis totais, estimado por Weiss, et al, (1992).

Total digestible nutrients, estimated by Weiss, et al, (1992).

O menor nível de bagaço utilizado, de $9 \%$ da matéria seca, representa o nível médio utilizado por seis consultores responsáveis por 3,6 milhões de cabeças confinadas anualmente nos estados americanos do Texas, Nebraska, Novo México, Oklahoma e Kansas (GALYEAN, 1996).
} 
seca do bagaço foi avaliado semanalmente e as dietas ajustadas em função dos resultados.

As pesagens dos animais foram realizadas no início do periodo de adaptação, no inicio do período experimental e a cada 28 dias até o abate, sempre com jejum hídrico e alimentar de 16 horas.

Foi medido teor de uréia no plasma sanguíneo dos animais através de teste enzimático colorimétrico com Kit industrial da biodiagnóstica (Pinhais-Paraná).

O delineamento experimental utilizado foi o inteiramente casualizado com arranjo fatorial 2x3, sendo dois tipos raciais (Continentais e Britânicos) e 3 níveis de bagaço in natura $(9,15$ e 21\% na MS), com 3 repetições de cada tratamento.

A análise de variância (teste F) foi usada para testar efeitos de tipo racial, nível de fibra (linear e quadrático) e a interação entre ambos. Para comparação de médias foi usado o teste Tukey. Todas as estimativas e testes estatísticos foram realizados usando o programa SAS (1997).

\section{Resultados e Discussão}

\section{Desempenho}

Os resultados do teor de nitrogênio na forma de uréia no plasma dos animais demonstraram valores de $14,9 \mathrm{mg} / \mathrm{dl}$ para os animais Continentais; $14,6 \mathrm{mg} / \mathrm{dl}$ para os animais Britânicos e $13,9 \mathrm{mg} / \mathrm{dl} ; 14,1 \mathrm{mg} / \mathrm{dl} ; 16,3 \mathrm{mg} / \mathrm{dl}$ para os tratamentos 9,15 e $21 \%$ respectivamente. Esses resultados sugerem que as dietas estavam adequadas às exigências nutricionais dos animais concordando com a simulação feita no CNCPS. O nível de proteína não deve ter sido limitante ao desempenho, inclusive para os animais Continentais. Estes resultados de PUN também parecem consistentes com os resultados das taxas de deposição de proteína medidas nestes animais (Capítulo 3) que não foram significativamente diferentes entre animais Britânicos e Continentais.

$\mathrm{Na}$ Tabela 2 são apresentados os resultados de desempenho animal e o nível de significância da interação entre tipo racial e nível de fibra na dieta. Não foram observados efeitos significativos da interação tipo racial $x$ nível de fibra para as características de desempenho analisadas. 
Tabela 2. Efeito do nível de fibra no desempenho de animais Britânicos e Continentais

Table 2. Effect of level of fiber on feedlot performance of British and Continental young bulls

\begin{tabular}{|c|c|c|c|c|c|c|c|}
\hline \multirow[t]{2}{*}{ Variáveis } & \multicolumn{3}{|c|}{$\begin{array}{l}\text { Nivel de } \mathrm{BIN} \\
\text { Level of } B I N^{2}\end{array}$} & \multicolumn{2}{|c|}{$\begin{array}{l}\text { Tipos Genéticos } \\
\text { Genetic groups }\end{array}$} & \multirow{2}{*}{$\begin{array}{l}\text { Inter- } \\
\text { ação } \\
\mathrm{RxF}^{6}\end{array}$} & \multirow[t]{2}{*}{$\mathrm{CV}^{5}$} \\
\hline & $9 \%$ & $15 \%$ & $21 \%$ & $\mathrm{C}^{3}$ & $\mathrm{~B}^{4}$ & & \\
\hline Número de Animais & 12 & 12 & 12 & 18 & 18 & & \\
\hline \multicolumn{8}{|l|}{ Number of Animals } \\
\hline Periodo Experimental (dias) & 139 & 139 & 139 & 139 & 139 & & \\
\hline \multicolumn{8}{|l|}{ Days of Experiment } \\
\hline Peso Inicial (kg) & $260,3^{a}$ & $258,9^{\mathrm{a}}$ & $252,6^{\mathrm{a}}$ & $256,0^{\mathrm{a}}$ & $258,5^{\mathrm{a}}$ & 0,37 & 3,64 \\
\hline \multicolumn{8}{|l|}{ Inicial Weight } \\
\hline Peso Final (kg) & $426,8^{\mathrm{ab}}$ & $448,7^{\mathrm{a}}$ & $424,8^{b}$ & $428,1^{\mathrm{a}}$ & $438,4^{a}$ & 0,40 & 3,52 \\
\hline \multicolumn{8}{|l|}{ Final Weight } \\
\hline Ganho Peso Vivo (kg/dia) & $1,20^{\mathrm{b}}$ & $1,36^{\mathrm{a}}$ & $1,24^{\mathrm{ab}}$ & $1,24^{\mathrm{a}}$ & $1,29^{\mathrm{a}}$ & 0,80 & 7,57 \\
\hline \multicolumn{8}{|l|}{ Daily Live Weight Gain } \\
\hline Consumo Matéria Seca (kg & $6,85^{\mathrm{b}}$ & $7,93^{\mathrm{a}}$ & $7,34^{\mathrm{ab}}$ & $7,20^{\mathrm{a}}$ & $7,54^{\mathrm{a}}$ & 0,57 & 7,69 \\
\hline \multicolumn{8}{|l|}{ MS/dia) } \\
\hline \multicolumn{8}{|l|}{ DryMatterintake } \\
\hline Consumo, $\%$ de Peso Vivo & $1,99^{b}$ & $2,24^{\mathrm{a}}$ & $2,16^{\mathrm{ab}}$ & $2,11^{\mathrm{a}}$ & $2,16^{\mathrm{a}}$ & 0,82 & 7,23 \\
\hline Dry Matter Intake, \% LW & & & & & & & \\
\hline Eficiência (kg GPV/kg MS) & $0,176^{\mathrm{a}}$ & $0,172^{\mathrm{a}}$ & $0,169^{\mathrm{a}}$ & $0,170^{\mathrm{a}}$ & $0,170^{\mathbf{a}}$ & 0,82 & 7,48 \\
\hline Efficiency & & & & & & & \\
\hline
\end{tabular}

Não houve diferenças significativas entre o desempenho de animais Britânicos e Continentais. O ganho de peso vivo dos animais Britânicos foi de $1,24 \mathrm{~kg} / \mathrm{dia}$ semelhante ao dos animais Continentais; $1,29 \mathrm{~kg} / \mathrm{dia}$.

Entre os três niveis crescentes de fibra estudados houve diferenças quanto ao ganho de peso vivo. O tratamento $15 \%$ de BIN na matéria seca apresentou ganho maior $(1,36 \mathrm{~kg} / \mathrm{dia})$ que os animais do tratamento $9 \%$ de BIN na matéria seca $(1,20$ $\mathrm{kg} /$ dia) sendo o tratamento $21 \%$ de BIN na matéria seca $(1,24 \mathrm{~kg} /$ dia $)$ intermediário. 
$\mathrm{O}$ consumo de matéria seca dos animais Britânicos $(7,20 \mathrm{~kg} \mathrm{MS} / \mathrm{dia})$ foi semelhante ao consumo dos animais Continentais $(7,54 \mathrm{~kg} \mathrm{MS} / \mathrm{dia})$. Entre os três niveis de fibra houve diferenças no consumo de matéria seca. Os animais que receberam dieta com $15 \%$ de BIN consumiram $7,93 \mathrm{~kg} \mathrm{MS} /$ dia, consumo significativamente superior que os animais tratados com $9 \%$ BIN na matéria seca que consumiram $6,85 \mathrm{~kg} \mathrm{MS} / \mathrm{dia}$, tendo o tratamento $21 \%$ de BIN na matéria seca um consumo intermediário; 7,34 $\mathrm{kg} \mathrm{MS} /$ dia, indicando que os animais recebendo níveis mais elevados de concentrado ( $9 \%$ da matéria seca total) reduziram seu consumo. A maior digestibilidade do amido aumenta o teor de energia líquida da dieta e consequentemente acaba por reduzir o consumo de matéria seca uma vez que em dietas de alto concentrado o consumo é controlado pela ingestão de energia.

Não houve diferença na eficiência de conversão alimentar dos dois tipos raciais; animais Britânicos e Continentais apresentaram eficiência de 0,170. Entre os três niveis de fibras, a eficiência foi estatisticamente a mesma, de 0,$176 ; 0,172$ e 0,169 para os níveis 9,15 e $21 \%$ de BIN. Estes resultados são interessantes pois sugerem que dietas de alto concentrado com bagaço in natura em níveis de $9 \%$ podem ser utilizadas.

BELTRAME FILHO (1998), analisando o BIN como fonte de volumoso quando comparado à silagem de milho obteve ganho de peso e eficiência de conversão alimentar superior para a silagem, apesar do consumo de matéria seca em relação ao peso vivo não diferir. No entanto, os resultados demonstram que o BIN tem potencial para ser utilizado em dietas de alto concentrado, mesmo apresentando resultados inferiores ao da silagem do milho, devido ao menor custo do BIN.

Uma possibilidade para o menor desempenho com BIN em relação à silagem poderia ser função do melhor valor nutricional da fibra da silagem. Entretanto, esta característica teria pouca relevância em função da baixa proporção dos volumosos e das baixas taxas de degradação da parede celular em dietas de alto concentrado. $O$ menor consumo de BIN em relação à silagem, poderia também ser explicado pela presença de fungos limitando o consumo uma vez que o armazenamento do BIN é crítico e o crescimento de fungos poderia levar à redução no consumo, entretanto, os efeitos de fonte de volumoso sobre o consumo não foram significativos. Uma terceira 
e real possibilidade seria a menor capacidade da fibra do BIN de manter um ambiente ruminal mais estável em função da menor efetividade da sua fibra.

Houve sensível redução no ganho de peso e consumo de alimentos no último periodo do experimento, provavelmente em função do intenso calor e da grande incidência de chuvas o que causou desconforto aos animais.

BARTLE et al (1994) encontrou um decréscimo linear do ganho de peso conforme aumentou-se o nível de volumoso. Houve uma pequena diferença entre 10 e $20 \%$ de volumoso, e um grande decréscimo em ganho entre 20 e $30 \%$ de volumoso $(0.7 \mathrm{~kg} / \mathrm{d})$.

O consumo de matéria seca em porcentagem do peso vivo não diferiu entre os dois tipos genéticos; os animais Britânicos consumiram 2,11\% PV e os animais Continentais $2,16 \% \mathrm{PV}$. Houve maior consumo para os animais recebendo dietas com maior teor de bagaço in natura (Tabela 2). O tratamento com $9 \%$ de BIN foi o que apresentou menor consumo em porcentagem do peso vivo, $1,99 \%$.

Aparentemente a maior proporção de concentrado e o menor consumo no tratamento $9 \%$ aumentaram a eficiência de utilização da dieta. Diversos estudos tem demonstrado o beneficio do fornecimento de dietas de alta energia com limitação de consumo. BARTLE e PRESTON (1991 e 1992) demonstraram que reduzindo o volumoso da dieta durante o meio e o período final pode-se melhorar eficiência do ganho e melhorar a qualidade da carcaça talvez devido a mudanças no padrão de crescimento, com menor crescimento ocorrendo no meio do período de alimentação. Dietas com $20-30 \%$ de volumoso podem também melhorar a qualidade da carcaça por diminuir a taxa de crescimento.

$O$ regime variável de forragem parece ser um instrumento para reduzir o uso de volumosos e diminuir os custos. Esta técnica poderia aumentar a digestibilidade, reduzir o teor de energia do ganho e consequentemente melhorar a eficiência alimentar. 


\section{Peso dos Órgãos}

A Tabela 3 apresenta o peso de alguns órgãos. Apesar de algumas tendências, não foram detectados efeitos significativos dos tratamentos para as variáveis. Entretanto, algumas características analisadas apresentaram efeito significativo da interação tipo racial $x$ nível de fibra. Dentre elas estão o peso dos rins e o peso do figado.

Tabela 3. Efeito do nivel de fibra nas características de carcaça de animais Britânicos e Continentais

Table 3. Effect of fiber level on carcass caracteristics of British and Continental bulls

\begin{tabular}{|c|c|c|c|c|c|c|c|}
\hline \multirow[t]{2}{*}{ Variáveis } & \multicolumn{3}{|c|}{$\begin{array}{l}\text { Nivel de } \mathrm{BIN}^{1} \\
\text { Level of } B I N^{2}\end{array}$} & \multicolumn{2}{|c|}{$\begin{array}{l}\text { Tipos Genéticos } \\
\text { Genetic groups }\end{array}$} & \multirow{2}{*}{$\begin{array}{c}\begin{array}{c}\text { Intera } \\
\text {-ção }\end{array} \\
\mathrm{RxF}^{6}\end{array}$} & \multirow[t]{2}{*}{$\mathrm{CV}^{5}$} \\
\hline & $9 \%$ & $15 \%$ & $21 \%$ & $\mathrm{C}^{3}$ & $\mathrm{~B}^{4}$ & & \\
\hline Número de animais & 12 & 12 & 12 & 18 & 18 & & \\
\hline \multicolumn{8}{|l|}{ Number of animals } \\
\hline $\begin{array}{l}\text { Período experimental } \\
\text { (dias) }\end{array}$ & 139 & 139 & 139 & 139 & 139 & & \\
\hline \multicolumn{8}{|l|}{ Days of experiment, days } \\
\hline Peso dos Rins (kg) & 0,85 & 0,83 & 0,87 & 0,82 & 0,88 & 0,05 & 13,8 \\
\hline \multicolumn{8}{|l|}{ Ktdney wetght } \\
\hline Peso do Figado (kg) & 5,54 & 5,76 & 5,56 & 5,48 & 5,69 & 0,03 & 10,8 \\
\hline \multicolumn{8}{|l|}{ Liver weight } \\
\hline Peso dos Rins \% PVfj & 0,19 & 0,19 & 0,21 & 0,19 & 0,20 & 0,18 & 15,4 \\
\hline \multicolumn{8}{|l|}{ Kidney weight $\% L W$} \\
\hline Peso do Fígado \% & 1,27 & 1,29 & 1,31 & 1,28 & 1,30 & 0,11 & 11,3 \\
\hline \multicolumn{8}{|l|}{ PVfj } \\
\hline Liver Weight $\% L W$ & & & & & & & \\
\hline
\end{tabular}

1 - Bagaço in natura; 2 - Bagasse in natura; 3 - Continental; 4 Britânico; British; 5 - Coeficiente de Variação; 6 - Interação Tipos Raciais x Fibra.

$\mathrm{O}$ peso da gordura renal e pélvica não apresentou diferenças quando comparados os dois tipos genéticos, Britânicos; $6,92 \mathrm{~kg}$ e Continentais; $6,14 \mathrm{~kg}$, embora os valores indiquem a maior tendência dos Britânicos em depositar gordura. A não observância de diferenças estatísticas parece estar relacionada ao baixo peso 
de abate, sendo mais baixo do que aquele em que ocorre deposição mais intensa de gordura. Quando analisada entre os três níveis de fibra, animais que receberam $9 \% \mathrm{e}$ $15 \%$ de BIN na matéria seca da dieta apresentaram acúmulo de gordura significativamente maior $(7,27 \mathrm{~kg}$ e $7,51 \mathrm{~kg}$ respectivamente) do que os animais que receberam $21 \%$ de BIN na matéria seca da dieta $(5,41 \mathrm{~kg}$ ) (RIBEIRO et al., 2000). Esse resultado é consistente já que os animais que receberam maior porcentagem de energia na dieta apresentaram maior deposição de gordura. Esta tendência a uma maior deposição de gordura foi observada em análises da composição da 9-11 costelas destes animais (Capítulo 3).

A ausência de diferenças marcantes nas caracteristicas de carcaça dos dois grupos genéticos, Britânicos e Continentais, parece esperada, em função das características deste experimento. Primeiro, o abate desses animais foi feito a pesos relativamente baixos, antes do início da fase exponencial de deposição de gordura. Isto é particularmente importante por serem animais inteiros. As diferenças talvez fossem detectadas se o abate tivesse sido a pesos mais elevados, quando a proporção de gordura no ganho é maior. Além desses fatores, a raça Continental utilizada, a Guelbvieh, é uma raça de tamanho corporal médio em relação a genótipos de elevado peso adulto característico das raças Continentais. Quando comparada a outra raça de tamanho corporal médio empregada neste trabalho, como a Shorthorn, as diferenças não se evidenciam. Resultados diferentes seriam esperados se a raça escolhida fosse a de elevado peso adulto e se a comparação envolvesse mais do que o efeito paterno. 


\section{Conclusões}

Houve efeito do nível de fibra na taxa de ganho. Dietas com $15 \%$ de bagaço de cana in natura apresentaram ganhos superiores aos níveis de 9 e $21 \%$. Entretanto não houve diferença na eficiência alimentar, provavelmente em função da queda no consumo para dietas de maior teor de concentrado. Estes resultados são consistentes com beneficios observados na limitação do consumo de dietas de alta energia.

Não foram observadas diferenças significativas para o efeito de tipos raciais paterno Continental (Gelbvieh) e Britânico (Shorthorn) para as características de desempenho e de carcaça. Estes resultados parecem consistentes com o baixo peso de abate, do fato de serem animais inteiros, e pelas características da raça Gelbvieh que diferem de raças Continentais de elevado peso adulto. 


\section{CAPÍTULO 3}

\section{EXIGÊNCIAS LÍQUIDAS DE ENERGIA E PROTEÍNA DE TOURINHOS DE DOIS GRUPOS GENÉTICOS ALIMENTADOS COM DIETAS DE ALTO TEOR DE CONCENTRADO}

RESUMO: Avaliou-se a composição corporal de 42 tourinhos $1 / 4 \mathrm{~B}$. indicus $x$ $3 / 4$ B. taurus, de raça paterna Britânica (Shorthorn) ou Continental (Gelbvieh) com 9 meses e $243 \mathrm{~kg}$ de peso vazio inicial. Destes, seis animais foram abatidos para a obtenção da composição corporal inicial do lote. Os 36 animais restantes foram confinados com dietas contendo 9,15 e $21 \%$ de bagaço de cana-de-açúcar in natura (BIN) na MS. Não houve interação entre os tipos genéticos e o nível de BIN. O efeito do tipo genético não alterou a composição do ganho de peso vazio, tendo os animais Britânicos apresentado $28,9 \%$ de lipídeo e 3,75 Mcal $/ \mathrm{kg}$, enquanto os animais Continentais apresentaram $28 \%$ de lipídeo e 3,67 Mcal $/ \mathrm{kg} \mathrm{GPVz}$. Os animais Britânicos tenderam a apresentar maiores teores de gordura e energia, apesar de apresentarem média de PVz inicial e final menores que os Continentais. O efeito de fibra não foi significativo, mas animais recebendo dietas com 15\% de BIN tenderam a apresentar ganho de peso vazio superior $(1,2 \mathrm{~kg} / \mathrm{d})$, aos que receberam $9 \%$ e $21 \%$ de $\operatorname{BIN}(1,1 \mathrm{~kg} / \mathrm{d})$. Os diferentes niveis de BIN não alteraram a composição do ganho, mas, consistente com a maior taxa de ganho, a composição do ganho de corpo vazio dos animais que receberam $15 \%$ de BIN tendeu a conter maiores teores de lipídeo e energia, $31 \%$ e $3,94 \mathrm{Mcal} / \mathrm{kg} \mathrm{GPVz}$. Os tratamentos 9 e $21 \%$ de BIN apresentaram respectivamente, $28,6 \%$ e $25,7 \%$ de lipídeo e 3,72 e $3,46 \mathrm{Mcal} / \mathrm{kg}$ de GPVz. A composição do ganho de corpo vazio e as exigências líquídas de energia e proteína dos tourinhos $3 / 4$ Europeus filhos de vacas Caracu $x$ Nelore com touros Gelbvieh ou Shorthorn foram semelhantes às observadas para machos não castrados de tamanho corporal grande ou de grau de estrutura corporal próximo a 8 na escala 19. 
Palavras Chaves: bagaço de cana, bovinos de corte, composição corporal, concentrado, exigências nutricionais, niveis de fibras

\section{NET ENERGY AND PROTEIN REQUIREMENTS OF YOUNG BULLS OF TWO GENETIC GROUPS FED HIGH CONCENTRATE DIETS}

ABSTRACT: Body composition of 42 crossbreed bulls $1 / 4 B$. indicus $x 3 / 4 B$. taurus of either Continental (Gelbvieh) or British (Shorthorn) paternal breed and Caracu $x$ Nelore cows were evaluated. Initial age was 9 months and initial empty body weight $243 \mathrm{~kg}$. Six were slaughtered to obtain the initial body composition. The other 36 animals were fed diets formulated with 9,15 and $21 \%$ of sugar cane bagasse (BIN) and concentrated. There were no interactions among genetic breed and level of BIN for any variable. There was no effect on paternal breed on the composition of empty body gain (EBG), with British animals $28,9 \%$ lipid and 3,75 Mcal $/ \mathrm{kg}$ and Continental animals $28 \%$ lipid and $3,67 \mathrm{Mcal} / \mathrm{kg}$. British animals tended to have greater fat content in the gains despite the lower initial and final empty body weights. Animals receiving diets with $15 \%$ BIN tended to have higher rates of empty body gain, $1,21 \mathrm{~kg} / \mathrm{d}$, while animals receiving $9 \%$ and $21 \%$, gained $1,1 \mathrm{~kg} / \mathrm{d}$. Roughage level or breed did not alter final empty body composition however, consistent with the faster gains composition of the empty body gain of animals fed $15 \%$ BIN tended to have a higher lipid and energy content, ( $31 \%$ and 3,94 Mcal $/ \mathrm{kg}$ of EBG) compared to the $9 \%$ and $21 \%$ BIN diets $(28,6$ and $25,7 \%$ lipid; 3,72 and $3,46 \mathrm{Mcal} / \mathrm{kg}$ of EBG respectively). These results can be explained by the animals being intact males at low final body weights. Composition of the empty body gain (net energy and protein requirements) of $3 / 4 B$. taurus $F_{2}$ crossbreed bulls from Caracu $x$ Nelore cows were consistent with NRC equation for large frame bulls or frame score 8 in a 1-9 scale.

Key Words: beef cattle, body composition, concentrate, fiber, requirements, sugarcane bagasse. 


\section{Introdução}

A determinação da composição corporal dos animais é fundamental para a avaliação do valor nutricional dos alimentos e em estudos do crescimento animal. $O$ crescimento normal de um animal deve ser entendido como um conjunto de modificações fisicas, químicas e funcionais de seu organismo (BOIN et al., 1994) onde há deposição dos componentes químicos. Através do conhecimento da composição química do ganho de peso é possível estudar a eficiência energética $e$ as exigências nutricionais do animal.

Para se determinar a composição corporal de animais, o método mais preciso envolve o abate do animal e a moagem de todos os tecidos corporais para posteriores análises laboratoriais. Entretanto, essa prática, como rotina experimental, é extremamente dispendiosa e trabalhosa.

Estudando diversas metodologias de estimativa da composição LANNA (1988), afirma que o uso da composição de cortes das costelas de bovinos produziu resultados mais confiáveis para se estimar a composição química corporal em relação à gravidade específica ou técnicas in vivo. HOPPER (1944) encontrou coeficientes de determinação para regressão do extrato etéreo no corte da $9^{\mathrm{a}}-11^{\mathrm{a}}$ costelas no corpo vazio de 0,96 ; e sugeriu que a melhor forma de se estimar a porcentagem de água e gordura seria através da composição química do corte das costelas. HENRIQUE et al (1999b) estabeleceram equações correlacionando a composição química da $9^{\mathrm{a}}-11^{\mathrm{a}}$ costelas com a composição química corporal especificamente para bovinos $5 / 8 \mathrm{~B}$. taurus, visto que as equações desenvolvidas para Nelore por LANNA (1988) não foram adequadas para este genótipo.

O nível de energia na dieta consumida pelo animal pode alterar a proporção de tecidos magros ou tecidos gordurosos depositados. Dietas de alto concentrado, onde o nível de energia consumida é alto, levam a um aumento na taxa de ganho e na concentração de gordura entre os tecidos depositados (FOX et al.,1992). Essa partição de energia para deposição de lipídeos e proteína, em animais com diferentes potenciais de deposição, foi estudada por ROBELIN e GEAY (1983) em animais recebendo dois níveis de energia. Uma maior proporção de energia foi retida como proteína nos animais com alto potencial de retenção de proteína, enquanto que um 
aumento da energia retida como lipídeos ocorreu nos animais com menor potencial de crescimento principalmente nas dietas de maior teor de energia. Assim, o tipo de animal parece influir na composição do ganho de peso em função da variação do nível de alimentação.

Segundo GILL e OLDHAN (1993) antes que a energia ingerida possa ser usada para síntese de novos tecidos, a demanda para manter os tecidos existentes deve ser atendida. $O$ requerimento de energia para mantença é definido como o nível de energia a ser suprido diariamente sem alteração da condição corporal. Seria a quantidade de energia metabolizável necessária e equivalente à produção de calor diária do animal.

Os requerimentos de energia líquida para crescimento (ELg) são estimados como a soma de energia depositada na forma de proteína e gordura. O NRC (1984, 1996) estima as exigências de energia para ganho, com base no peso médio e ganho de peso diário. Os requerimentos são ajustados de acordo com as condições específicas, como tamanho do animal, sexo e uso de implantes e hormônios. $\mathrm{O}$ sistema de Cornell (FOX et al., 1992), usa equações semelhantes às do NRC (1984) para predizer os requerimentos nutricionais, consumo e eficiência de utilização da energia dos alimentos. Entretanto são considerados os efeitos de vários fatores sobre estas equações incluíndo: tamanho e condição corporal, estádio de crescimento, frações das proteínas e dos carboidratos nos alimentos, suas taxas de digestão e passagem e condições ambientais.

Existem poucos dados das exigências líquidas de mestiços zebuínos quando comparados ao grande volume de informações disponíveis para a estimativa das exigências nutricionais de taurinos (NRC, 1996). Este trabalho visa a obtenção de dados da composição corporal de mestiços e zebuínos que possam parametrizar modelos como o CNCPS (FOX et al., 1992) e o RLM (LANNA et al, 1999). Os resultados obtidos podem ser utilizados para atualizar as equações destes modelos, permitindo a análise dos requerimentos nutricionais de forma dinâmica e cada vez mais acurada e precisa.

Diversos grupos vem pesquisando o efeito das dietas (natureza do alimento, concentração energética, tipo de fibra, periodo de alimentação, etc.) e dos animais (raça, idade, sexo, condição corporal ou nivel de nutrição anterior) sobre crescimento 
e a composição do ganho de peso de bovinos em crescimento. No Brasil, a partir da década de 80 , trabalhos foram conduzidos no sentido de obter informações que permitam fazer estimativas de exigências nutricionais que mais se adequem às condições brasileiras (LANA et al., 1992; LEME et al, 1994; BOIN, 1995; FONTES et al., 1995; LANNA et al., 1995; ALLEONI et al., 1997; HENRIQUE et al, 1999a; HENRIQUE et al, 1999b) e adaptar informações básicas oriundas de outros paises à realidade brasileira (LANNA et al., 1999).

A redução da proporção de volumoso está geralmente ligada a um aumento no teor de energia da dieta e consequentemente a um aumento na taxa de ganho e proporção de gordura no ganho. Outro aspecto importante é o de que a manipulação do teor de volumoso deve ser feita de forma a atender as exigências mínimas de fibra efetiva para ruminantes. Programas de formulação capazes de encontrar o teor de energia ótimo para maximizar lucro devem incluir restrições para manter os níveis de fibra efetiva que evitem o aparecimento de distúrbios metabólicos. Estes valores tem se mostrado diferentes para zebuínos e animais europeus e seus cruzamentos (LANNA et al., 1999).

Uma possivel fonte de volumoso para dietas de confinamento no Brasil seria o bagaço de cana-de-açúcar in natura. Este alimento apresenta um grande excedente e tradicionalmente vem sendo utilizado após tratamento fisico ou químico. Poucos estudos foram conduzidos com o bagaço in natura em dietas de alto concentrado (HENRIQUE et al., 1999a) e não se conhece o nível ideal de utilização neste tipo de dieta. Esta questão é importante pois o bagaço sem tratamento não se caracteriza como uma boa fonte de fibra íntegra, em função de conter grande proporção de partículas de pequeno tamanho e possibilidade de crescimento de fungos.

O objetivo deste trabalho foi estimar a composição corporal e as exigências líquidas de energia e proteína de mestiços $\mathrm{F}_{2}$ de tipos genéticos paternos Continentais e Britânicos filhos de vacas Caracu x Nelore (bezerros 3/4 sangue Europeu, 1/4 sangue Zebuíno e $1 / 2$ sangue de animais adaptados). Os animais foram alimentados com dietas de alto concentrado com três níveis de bagaço de cana-de-açúcar in natura com objetivo de avaliar o BIN como único volumoso. 


\section{Material e Métodos}

Foram confinados 42 tourinhos cruzados $(3 / 4$ de sangue Europeu, $1 / 4$ sangue Zebu), com idade média de 9 meses e peso vazio de $243 \mathrm{~kg}$ ao início do período experimental em 18 baias parcialmente cobertas, 2 animais por baia. O periodo de confinamento foi de julho de 1998 a janeiro de 1999. Os animais eram filhos de vacas Caracu $\mathrm{x}$ Nelore, sendo as raças paternas a Britânica Shorthorn ou a Continental Gelbvieh.

Os animais distribuidos aleatoriamente dentro da instalação receberam durante 42 dias de adaptação uma dieta com níveis crescentes de volumoso até chegarem a $21 \%$ de bagaço in natura. Após esse período, foram abatidos seis animais para determinação do peso vazio e da composição química corporal inicial do lote. Os animais restantes foram alimentados por mais 139 dias. O volumoso utilizado durante o experimento foi bagaço in natura, e o concentrado composto de farelo de soja, soja extrusada, milho, e polpa de citrus. As dietas continham 3 níveis de bagaço de cana-de-açúcar in natura (BIN) - 9, 15 e 21\% da matéria seca total e foram balanceadas de acordo com o modelo do Cornell Net Carbohydrate and Protein System - CNCPS (FOX et al., 1992), para atender as exigências de proteína degradável no rúmen e proteína metabolizável para o animal, bem como as exigências de aminoácidos e peptídeos no rúmen (Tabela 1). 
Tabela 1. Composição das dietas experimentais (\% na matéria seca)

Table 1. Composition of the experimental diets (\% in dry matter)

\begin{tabular}{|c|c|c|c|}
\hline \multirow{2}{*}{$\begin{array}{l}\text { NGREDIENTES } \\
\text { Ingredients }\end{array}$} & \multicolumn{3}{|c|}{$\begin{array}{l}\text { NIVEL DE BAGAÇO IN NATURA, } \\
\text { Level of Sugarcane Bagasse in natura }\end{array}$} \\
\hline & $9 \% \mathrm{BIN}$ & $15 \% \mathrm{BIN}$ & $21 \% \mathrm{BIN}$ \\
\hline Bagaço de cana & 9,0 & 15,0 & 21,0 \\
\hline \multicolumn{4}{|l|}{ Sugarcane Bagasse } \\
\hline Farelo de soja & 8,5 & 9,6 & 10,3 \\
\hline \multicolumn{4}{|l|}{ Soybean meal } \\
\hline Soja extrusada & 4,5 & 4,5 & 4,5 \\
\hline \multicolumn{4}{|l|}{ Extruded soybean meal } \\
\hline Milho moído & 45,1 & 40,9 & 37,1 \\
\hline \multicolumn{4}{|l|}{ Grounded corn } \\
\hline Polpa cítrica & 31,0 & 27,9 & 25,1 \\
\hline \multicolumn{4}{|l|}{ Citrus pulp } \\
\hline Cloreto de potássio & 0,1 & 0,1 & 0,1 \\
\hline \multicolumn{4}{|l|}{ Potassium chloride } \\
\hline Sal mineralizado & 0,8 & 0,8 & 0,8 \\
\hline \multicolumn{4}{|l|}{ Mineral sait } \\
\hline Rumensin & 0,03 & 0,03 & 0,03 \\
\hline \multicolumn{4}{|l|}{ Rumensin } \\
\hline Uréia & 1,0 & 1,0 & 1,0 \\
\hline \multicolumn{4}{|l|}{ Urea } \\
\hline \multicolumn{4}{|l|}{ NUTRIENTES } \\
\hline \multicolumn{4}{|l|}{ Nutrients } \\
\hline Proteína bruta, \% & 14,6 & 14,6 & 14,5 \\
\hline \multicolumn{4}{|l|}{ Crude protein,\% } \\
\hline NDT, $\%^{1}$ & 78,8 & 75,4 & 72,0 \\
\hline
\end{tabular}

${ }^{1}$ Nutrientes digestiveis totais, estimado por Weiss, et al, (1992).

Total digestible nutrients, estimated by Weiss, et al, (1992).

Os alimentos foram fornecidos na forma de ração completa, em duas refeições diárias e amostras de alimentos e sobras coletadas para análise. $O$ teor de matéria seca foi avaliado no bagaço semanalmente e as dietas ajustadas em função dos resultados. As pesagens dos animais foram realizadas no início do período de 
adaptação, no início do período experimental e a cada 28 dias até o abate, sempre com jejum hídrico e alimentar de 16 horas.

Ao final do período experimental, os animais foram abatidos para determinação da composição química corporal e das características da carcaça. A estimativa da composição foi feita com base nas porcentagens de proteína, lipídeos, água e minerais obtidas através da análise química do corte da $9-11^{\mathrm{a}}$ costelas, retirada como descrito por HANKINS \& HOWE (1946).

Após a retirada do corte, foi feita a pesagem seguindo-se a separação física de músculos, ossos, cartilagens e gordura, pesando-as separadamente em seguida. As pesagens foram anotadas para posterior cálculo da composição física. As amostras do corte foram moídas 8 vezes em moedor de grande porte (Hermann P-33 ${ }^{A}-3-789,15$ HP), homogeneizadas e amostradas em quadruplicata. Posteriormente foram liofilizadas para determinação da concentração de água. A amostra liofilizada foi moída em liquidificador com gelo seco e analisadas para extrato etéreo (aparelho soxhlet por 20 horas), proteína ( $\mathrm{N}$ - total) e cinzas (mufla a 600C).

Utilizando-se equações desenvolvidas para estimar a composição química corporal de bovinos Santa Gertrudis (HENRIQUE et al., 1999b), com base nas porcentagens de água e lipídeos na seção da $9^{\mathrm{a}}-11^{\mathrm{a}}$ costelas, determinou-se as porcentagens destes no corpo vazio. O peso do corpo vazio $(\mathrm{PVz})$ foi estimado a partir do peso da carcaça quente (PCQ). A determinação do conteúdo corporal de energia foi feita a partir dos teores corporais de proteína e gordura e dos respectivos equivalentes calóricos (BOIN, 1995).

O delineamento experimental foi inteiramente casualizado com arranjo fatorial $3 \times 2$, sendo dois tipos raciais (Continentais e Britânicos) e 3 níveis de bagaço in natura $(9,15$ e $21 \%$ na MS), com 3 repetições de cada tratamento. A análise de variância (teste F) foi usada para testar efeitos do tipo racial, nível de fibra e da interação entre ambos. Para comparação de médias foi usado o teste Tukey. Todas as análises estatísticas foram realizadas usando o programa SAS (1997). 


\section{Resultados e Discussão}

Os resultados de composição química corporal ao abate e das taxas de deposição de tecidos ao longo do período de confinamento estão apresentados nas Tabelas 2 e 3 . A composição química corporal do ganho de peso ocorrido entre o final do período de adaptação e abate estão apresentados na Tabela 4. Como esperado, para todos os fatores estudados não houve interação significativa entre os tipos genéticos paternos (Britânicos e Continentais) e os níveis de volumosos ( $9 \%$, $15 \%$ e $21 \%$ de Bagaço de cana-de-açúcar in natura na MS da dieta). Isto se explica pelo fato de que todas as dietas são caracterizadas por altos niveis de concentrado e em função dos animais terem composição genética bastante similar.

Tabela 2. Composição química corporal e ganhos diários no período

Table 2. Body chemical composition and daily gain

\begin{tabular}{|c|c|c|c|c|c|c|c|}
\hline \multirow[t]{2}{*}{ Variáveis } & \multicolumn{3}{|c|}{$\begin{array}{l}\text { Nível de BIN } \\
\text { Level of } B I N^{2}\end{array}$} & \multicolumn{2}{|c|}{$\begin{array}{l}\text { Tipos Genéticos } \\
\text { Genetic Type }\end{array}$} & \multirow{2}{*}{$\begin{array}{l}\text { Intera- } \\
\text { ção } \\
\mathrm{RxF}^{5}\end{array}$} & \multirow[t]{2}{*}{$\mathrm{CV}^{6}$} \\
\hline & $9 \%$ & $15 \%$ & $21 \%$ & $\mathrm{C}^{3}$ & $\mathrm{~B}^{4}$ & & \\
\hline Peso Vazio Inicial (kg) & 245,7 & 244,7 & 238,7 & 251,5 & 234,6 & 0,84 & 12,57 \\
\hline \multicolumn{8}{|l|}{ Initial Empty Body Weight } \\
\hline Peso Vazio Final (kg) & 401,8 & 418 & 396,5 & 409,9 & 401,0 & 0,77 & 11,28 \\
\hline \multicolumn{8}{|l|}{ Final Empty Body Weight } \\
\hline Ganho Peso Vazio (g/d) & 1.100 & 1.210 & 1.110 & 1.100 & 1.180 & 0,76 & 17,04 \\
\hline \multicolumn{8}{|l|}{ DailyEmpty Body Gain } \\
\hline Água g/d & 528 & 563 & 569 & 537 & 569 & 0,97 & 26,11 \\
\hline \multicolumn{8}{|l|}{ Water } \\
\hline Extrato Etéreo g/d & 316 & 374 & 283 & 311 & 337 & 0,42 & 35,03 \\
\hline \multicolumn{8}{|l|}{ Etereo Extract } \\
\hline Proteina $\mathrm{g} / \mathrm{d}$ & 203 & 223 & 207 & 204 & 218 & 0,87 & 17,59 \\
\hline \multicolumn{8}{|l|}{ Crude Protein } \\
\hline Cinza $g / d$ & 50 & 55 & 51 & 50 & 54 & 0,88 & 17,65 \\
\hline \multicolumn{8}{|l|}{$A s h$} \\
\hline Energia Mcal/d & 4,11 & 4,77 & 3,81 & 4,07 & 4,39 & 0,41 & 26,93 \\
\hline Energy & & & & & & & \\
\hline
\end{tabular}


Embora tenha sido observada uma tendência para maior deposição de gordura para os animais de raça paterna Britânica, este não foi significativo para a maioria das variáveis estudadas. Esse resultado pode ser função de alguns fatores. Primeiro, como os animais eram inteiros e abatidos com baixo peso corporal (405 kg PVz) não foi possivel detectar diferenças já que estas se manifestam de forma mais clara posteriormente, no período em que há deposição mais intensa de gordura (i.e. a pesos mais elevados). Uma segunda razão seria o fato de que as diferenças genéticas se limitavam ao efeito paterno, ou $50 \%$ da contribuição genética. A terceira razão para as pequenas diferenças encontradas entre os dois tipos genéticos é que a raça Guelbvieh possui tamanho intermediário, sem as características marcantes de elevado peso adulto de algumas raças Continentais. Quando comparados ao mesmo peso vivo, animais de tamanho corporal pequeno apresentam maior teor de gordura e menor teor de proteína que animais de tamanho corporal grande. Consequentemente animais de maior tamanho corporal tem menor exigência de energia e maior exigência de proteína por quilo de ganho. Essas características não foram observadas na comparação destas raças, devido às características de tamanhos corporais intermediários de ambas as raças. 
Tabela 3. Composição do corpo vazio ao abate, $\%$

Table 3. Final empty body composition

\begin{tabular}{|c|c|c|c|c|c|c|c|}
\hline \multirow[t]{2}{*}{ Variáveis } & \multicolumn{3}{|c|}{$\begin{array}{c}\text { Nivel de BIN } \\
\text { Level of } B I N^{2}\end{array}$} & \multicolumn{2}{|c|}{$\begin{array}{l}\text { Tipos Genéticos } \\
\text { Genetic Type }\end{array}$} & \multirow{2}{*}{$\begin{array}{l}\text { Intera- } \\
\text { ção } \\
\mathrm{RxF}^{5}\end{array}$} & \multirow[t]{2}{*}{$\mathrm{CV}^{6}$} \\
\hline & $9 \%$ & $15 \%$ & $21 \%$ & $\mathrm{C}^{3}$ & $B^{4}$ & & \\
\hline Água & 58,0 & 56,7 & 59,1 & 58,3 & 57,7 & 0,42 & 5,46 \\
\hline \multicolumn{8}{|l|}{ Water } \\
\hline Extrato Etéreo & 18,2 & 19,5 & 17,0 & 17,9 & 18,6 & 0,42 & 18,7 \\
\hline \multicolumn{8}{|l|}{ E Extract } \\
\hline Proteina & 19,1 & 19,0 & 19,2 & 19,1 & 19,1 & 0,42 & 1,02 \\
\hline \multicolumn{8}{|l|}{ Crude Protein } \\
\hline Cinza & 4,71 & 4,69 & 4,73 & 4,72 & 4,71 & 0,48 & 1,02 \\
\hline \multicolumn{8}{|l|}{ Ash } \\
\hline Energia Mcal/kg & 2,76 & 2,89 & 2,66 & 2,74 & 2,80 & 0,48 & 11,31 \\
\hline Energy Mcal/kg & & & & & & & \\
\hline
\end{tabular}

1 - Bagaço in natura ; 2 - Bagasse in natura; 3 - Continental; 4 - Britânicos / British 5 - Interação Raça x Fibra; 6 - Coeficiente de variação.

Entretanto, a deposição de gordura para os animais Britânicos foi cerca de $8 \%$ maior do que para animais Continentais, sugerindo que o genótipo Gelbvieh apresenta tendência de maior proporção de músculo no ganho. $\mathrm{O}$ teor de lipídeo no ganho de cerca de $28 \%$ e o teor de lipídeo final de $18 \%$ aos $400 \mathrm{~kg}$ de peso vazio foi menor do que dados da literatura para touros Britânicos (ANRIQUE, 1976; SIMPFENDORFER, 1974). Na Figura 1 está representada a relação entre peso do corpo vazio e da gordura de touros Angus e Holandeses comparados com os animais Britânicos e Continentais deste experimento. Os resultados sugerem que os tourinhos deste experimento apresentavam composição próxima a tourinhos Holandeses. Com animais Santa Gertrudis, BERNDT, et al (1999) encontraram teor de lipídeo no ganho de $42 \%$ e o teor de lipídeo final de $22 \%$ aos $407 \mathrm{~kg}$ de peso vazio, embora estes animais tenham recebido suplementação pré-desmama e maior tempo de confinamento. 
Trabalhando com animais de dois anos de idade LANNA et al (1997) estudaram a composição corporal de três diferentes grupos genéticos Nelore, Nelore x Marchigiana, e mestiços leiteiros com sangue Holandês e encontraram teores de lipídeo no corpo vazio final de $19 \%, 16 \%$ e 18\% respectivamente. Estes teores baixos de gordura, apesar do elevado peso de abate $(\sim 500 \mathrm{~kg})$, também são função dos animais serem machos inteiros, além de estarem em crescimento compensatório. $\mathrm{Na}$ verdade, a maior parte dos abates no Brasil são realizados com baixa proporção de gordura, seja com bois confinados após período prolongado de pastejo, seja com garrotes confinados imediatamente após a desmama, como no presente trabalho, mas abatidos com pesos inferiores a $480 \mathrm{~kg}$. Comparativamente, os teores de lipídeos nos animais abatidos nos EUA e Canadá são de cerca de $28 \%$. Quando os abates são conduzidos neste grau de acabamento as diferenças raciais são mais evidentes.

Figura 1. Deposição de gordura em tourinhos deste trabalho e comparação com dados da literatura.

Picture 1. Deposition of body fat in bulls from this trial and from the literature.

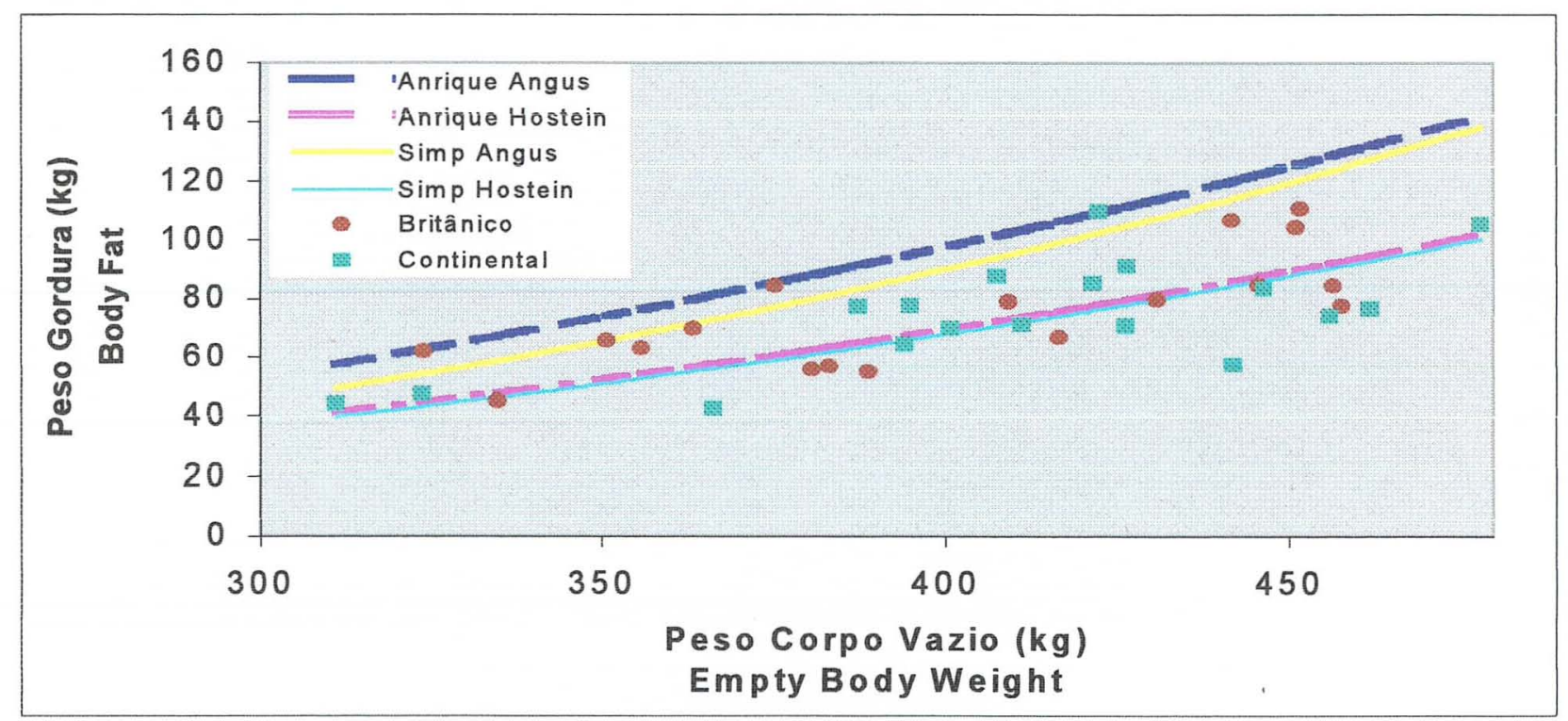

Anrique Angus Bulls: $y=2.7803-0.03778 x+0.0006872 x^{2}$

Anrique Holstein Bulls: $y=17.5808-0.11076 x+0.0005997 x^{2}$ In: (Anrique, 1976)

Simpfendorfer Angus Bulls: $y=28.429-0.2342 x+0.00097 x^{2}$

Simpfendorfer Holstein Bulls: $y=16.403-0.1115 x+0.00060 x^{2}$ In: (Simpfendorfer, 1974) 
Tabela 4.Composição do Ganho de Corpo Vazio, \%

Table 4. Composition of the empty body gain

\begin{tabular}{|c|c|c|c|c|c|c|c|}
\hline \multirow[t]{2}{*}{ Variáveis } & \multicolumn{3}{|c|}{$\begin{array}{l}\text { Nivel de BIN } \\
\text { Level of } B I N^{2}\end{array}$} & \multicolumn{2}{|c|}{$\begin{array}{l}\text { Tipos Genéticos } \\
\text { Genetic Type }\end{array}$} & \multirow{2}{*}{$\begin{array}{l}\begin{array}{c}\text { Intera- } \\
\text { ção }\end{array} \\
\mathrm{RxF}^{5}\end{array}$} & \multirow[t]{2}{*}{$\mathrm{CV}^{6}$} \\
\hline & $9 \%$ & $15 \%$ & $21 \%$ & $\mathrm{C}^{3}$ & $B^{4}$ & & \\
\hline Água & 48,4 & 46,1 & 51,0 & 48,9 & 48,1 & 0,64 & 18,38 \\
\hline \multicolumn{8}{|l|}{ Water } \\
\hline Extrato etéreo & 28,6 & 31,0 & 25,7 & 28,0 & 28,9 & 0,64 & 33,75 \\
\hline \multicolumn{8}{|l|}{ E Extract } \\
\hline Proteina & 18,5 & 18,4 & 18,7 & 18,5 & 18,5 & 0,64 & 2,97 \\
\hline \multicolumn{8}{|l|}{ Crude protein } \\
\hline Cinza & 4,57 & 4,53 & 4,61 & 4,58 & 4,56 & 0,65 & 2,99 \\
\hline \multicolumn{8}{|l|}{ Ash } \\
\hline Energia Mcal/kg & 3,72 & 3,94 & 3,46 & 3,67 & 3,75 & 0,64 & 23,76 \\
\hline Energy Mca/kg & & & & & & & \\
\hline
\end{tabular}

1 - Bagaço in natura; 2 - Bagasse in natura; 3 - Continental; 4 - Britânicos / British 5 - Interação Raça $x$ Fibra; 6 - Coeficiente de variação.

O efeito de fibra não foi significativo para as variáveis estudadas, mas os animais recebendo dietas com $15 \%$ de BIN tenderam a uma maior taxa de ganho de peso vazio. Consistente com este ganho maior, a composição do ganho tendeu a conter maior porcentagem de extrato etéreo (Tabelas 2 e 4). Trabalhos anteriores do nosso grupo demonstraram que o BIN apresentou resultados de desempenho inferiores aos da silagem de milho, quando usado como única fonte de fibra para dietas de alto concentrado (HENRIQUE et al.,1999a). BERNDT et al (1999) comparando milho seco ou ensilado úmido associado a silagem de milho ou BIN em tourinhos Santa Gertrudis verificou uma redução no teor de energia líquida da dieta contendo BIN. Houve também uma tendência de aumento no teor de gordura final no corpo vazio dos animais que receberam silagem em relação àqueles que receberam BIN fato este que pode estar ligado ao maior ganho de peso e peso vazio final dos animais recebendo silagem. Em função da baixa variação na taxa de ganho não se esperava encontrar, neste trabalho, grandes diferenças na composição do ganho dos animais alimentados com os três diferentes níveis de fibra. 
Os resultados do teor de nitrogênio na forma de úreia no plasma dos animais estão de acordo com a composição das dietas e com as taxas de deposição de proteína observadas, não havendo diferenças entre os dois tipos genéticos estudados; Britânicos $(14,61 \mathrm{mg} / \mathrm{dl})$ e Continentais $(14,92 \mathrm{mg} / \mathrm{dl})$ e entre os três niveis de fibra $9 \%(13,89 \mathrm{mg} / \mathrm{dl}) ; 15 \%(14,12 \mathrm{mg} / \mathrm{dl}) ; 21 \%(16,29 \mathrm{mg} / \mathrm{dl})$.

\section{Conclusões}

As composições do corpo vazio e do ganho de corpo vazio de tourinhos $3 / 4$ europeus filhos de vacas Caracu x Nelore foram similares às observadas para animais europeus de tamanho corporal grande. Na faixa de peso estudada, a concentração de

energia no ganho de peso foi menor do que a estimada para tourinhos de tamanho corporal médio (NRC, 1984).

Os diferentes níveis de BIN não alteraram a composição do ganho, consistente com a pequena diferença no ganho de peso entre os tratamentos.

Até o peso de abate estudado, não houve efeito da raça paterna, Gelbvieh ou Shorthorn, na composição do ganho, apesar de uma tendência para o ganho da última conter mais gordura. Estes resultados podem ser utilizados para parametrizar modelos de simulação do desempenho e de estimativa das exigências nutricionais. 


\section{CAPÍTULO 4 CONCLUSÕES FINAIS}

Pelos resultados de desempenho, de características da carcaça e da composição corporal avaliados é possível inferir que não houve grandes diferenças entre animais de raça paterna Britânica e Continental. Essa semelhança dos resultados provavelmente está relacionada ao fato de que a diferença se limita ao efeito paterno, em função do baixo peso de abate, do fato dos animais serem inteiros e também pelas características da raça Guelbieh que apresenta menor peso adulto que a maioria das raças Continentais.

Embora não tenha sido demonstrado efeito da raça paterna, Guelbvieh ou Shorthorn na composição do ganho, até o peso de abate estudado, houve uma tendência para o ganho da última conter mais gordura. A composição do ganho de corpo vazio e as exigências líquidas de energia e proteína dos tourinhos $3 / 4$ Europeus filhos de vacas Caracu $x$ Nelore com touros Gelbvieh ou Shorthorn foram semelhantes às observadas para machos não castrados de tamanho corporal grande ou de grau de estrutura corporal 8, na escala de 1-9.

Dietas com $15 \%$ de BIN apresentaram ganhos superiores aos niveis de $9 \%$ e $21 \%$ de BIN. Entretanto não houve diferença na eficiência alimentar, provavelmente em função da queda no consumo da dieta de maior teor de concentrado, sugerindo que dietas de alto concentrado e níveis de bagaço in natura de apenas $9 \%$ podem ser utilizados

Os diferentes niveis de BIN não alteraram a composição do ganho provavelmente porque todas as dietas apresentavam alta proporção de concentrado e da consequente pequena diferença no ganho de peso entre os tratamentos. Entretanto, consistente com o maior ganho de peso os animais recebendo dietas com $15 \%$ de BIN tenderam a uma maior taxa de ganho de peso vazio e a composição do ganho tendeu a conter maior porcentagem de extrato etéreo. 
Os resultados deste trabalho podem ser utilizados para parametrizar modelos de simulação de desempenho e de estimativa das exigências nutricionais. Os resultados também demonstram que o BIN pode ser usado como único volumoso em dietas de alta proporção de concentrados. 


\section{Referências Bibliográficas}

ALLEONI, G.F. Avaliação da gravidade específica da carcaça, da composição química e fisica, dos cortes da costela para estimar a composição corporal de novilhos Nelore na fase de acabamento. Jaboticabal, 1995. 59p Tese (Doutorado) - Faculdade de Ciências Agrárias e Veterinárias de Jaboticabal, Universidade Estadual Paulista "Julio de Mesquita Filho".

ALLEONI, G.F.; LEME, P.R.; BOIN, C. et al. Métodos indiretos para estimar a composição química da carcaça de novilhos nelore. 2. Cortes da costela. In: REUNIÃO ANUAL DA SOCIEDADE BRASILEIRA DE ZOOTECNIA, 34. Juiz de Fora, 1997. Anais. Juiz de Fora: SBZ, 1997, p 320-322

ANRIQUE, R. Body composition and efficiency of cattle as related to body type, size and sex. Ithaca, 1976. 211p. Thesis (PhD) - Cornell University.

BARTLE, S.J.; PRESTON, R.L. Dietary roughage regime for feedlot steers: reduced roughage level (2\%) during the midfinishing period. Journal of Animal Science, v.69, n.9, p.3461-3466, 1991.

BARTLE, S.J.; PRESTON, R.L. Roughage level and limited maximum intake regimes for feedlot steers. Journal of Animal Science, v.70, n.11, p.3293-3303, 1992.

BARTLE, S.J.; PRESTON, R.L.; MILLER, M.F. Dietary energy source and density: effects of roughage source, roughage equivalent, tallow level, and steer type on feedlot performance and carcass characteristics. Journal of Animal Science, v.72, n.8, p. 1943-1953, 1994.

BELTRAME FILHO, J.A. Eficiência energética e composição corporal de bovinos em crescimento. Piracicaba, 1998. 27p. Relatório (Graduação) - Escola Superior de Agricultura "Luiz de Queiroz", Universidade de São Paulo.

BERNDT, A; LANNA, D. P. D.; LEME, P. R et al. Milho úmido, bagaço de cana e silagem de milho em dietas de alto concentrado. 2. Composição corporal e taxas de deposição dos tecidos In: REUNIÃO ANUAL SOCIEDADE BRASILEIRA DE ZOOTECNIA, 36., Porto Alegre, 1999. Anais. Porto Alegre: SBZ, 1999. p. 285. 
BOIN, C. Alguns dados sobre exigências de energia e de proteína de zebuínos. Simpósio Internacional sobre exigências nutricionais de ruminantes. Universidade Federal de Viçosa. Viçosa- MG, 24-26 outubro, 1995. 457-465.

BOIN, C.; LEME, P.R.; LANNA, D.P.D. et al. Tourinhos Nelore em crescimento e acabamento. 2. Exigências de energia líquida de mantença e eficiência de utilização da energia metabolizável para mantença e crescimento. In: REUNIÃO ANUAL DA SOCIEDADE BRASILEIRA DE ZOOTECNIA, 31., Maringá, 1994. Anais. Maringá: SBZ, 1994. p.473.

BRODY, S. Bioenergetics and growth. New York: Hafner Publ., 1968.

BURGI, R. Produção de bagaço de cana-de-açúcar auto hidrolizado e avaliação do seu valor nutritivo para ruminantes. Piracicaba, 1985. Dissertação (Mestrado) Escola Superior de Agricultura 'Luiz de Queiroz', Universidade de São Paulo.

BYERS, F.M. Protein growth and turnover in cattle: systems for measurement and biological limits. protein requeriments for cattle. In: SYMPOSIUM OKLAHOMA STATE UNIVERSITY, Oklahoma, 1980. Proceedings. Oklahoma: Oklahoma State University, 1980. p 141-165

BYERS, F.M.; GOODALL, S.R. Effect of energy level on ruminal $\mathrm{D}(-)$ and $\mathrm{L}\left({ }^{+}\right)$ lactic acid metabolism. Journal of Animal Science, v.18, p.621-632, 1979.

CASTRO, F.B. Avaliação do processo de digestão do bagaço de cana-de-açúcar auto hidrolizado em bovinos. Piracicaba, 1989. 123p. Dissertação (Mestrado) Escola Superior de Agricultura 'Luis de Queiroz', Universidade de São Paulo.

EZEQUIEL, J.M.B.; ANDRADE, P. Avaliação de rações contendo bagaço de canade-açúcar e palha de arroz. Ingestão e digestibilidade. Revista da Sociedade Brasileira de Zootecnia, v. 17, n.5, p.116-155, 1988.

FELICIO, P.E. Fatores ante e post mortem que influenciam na qualidade da carne bovina. In: SIMPÓSIO SOBRE PECUÁRIA DE CORTE, 4., Piracicaba, 1996. Anais. Piracicaba: FEALQ, 1996. p.79-98.

FNP CONSULTORIA E COMÉRCIO. ANUALPE 97: anuário da pecuária brasileira. São Paulo,1997. p. 194: Custo de produção de silagens.

FONTES, C.A.A. Composição corporal, exigências líquidas de nutrientes para ganho de peso e desempenho produtivo de animais zebuínos e mestiços europeu-zebu. Resultados experimentais. In: SIMPÓSIO INTERNACIONAL SOBRE 
EXIGÊNCIAS NUTRICIONAIS DE RUMINANTES, Viçosa, 1995. Viçosa: Universidade Federal de Viçosa, 1995. p.419-455.

FORTIN, A.; SIMPFENDORFER, S.; REID, J.T. et al. Effect of level of energy intake and influence of breed and Sex on the chemical composition of cattle. Journal of Animal Science, v.51, p.3, 1980.

FOX, D.G.; SNIFFEN, C.J.; O' CONNOR, J.D. et al. A net carbohydrate and protein system for evaluating cattle diets: III. Cattle requeriments and diet adequacy. Journal of Animal Science, v.70, p. 3578-3596, 1992.

FRISH, J. E.; VERCOE, J. E. Food intake, eating rate, weight gains, metabolic rate and efficiency of feed utilization in Bos taurus and Bos indicus crossbred cattle. Animal Production, v.25, p. 343, 1977.

FULTON, W.R.; KLOPFENSTEIN, T.J.; BRITTON, R.A. Adaptation to high concentrate diets by beef cattle. I. Adaptation to corn and wheat diets. Journal of Animal Science, v.49, p.775-784, 1979.

GALYEAN, M.L. Protein levels in beef cattle finishing diets: industry application, university research, and systems results. Journal of Animal Science, v.74, n.11, p. $2860-2870,1996$.

GARRET, W.N. Energy utilization by growing cattle as determinad in 72 comparative slaughter experiments. Energy Metabolism Proceedings Symposium, v. 26, p.3-7, 1979.

GILL, M. , OLDHAN, J.D. Growth. In: FORBES, J.M.; FRANCE, J. (Ed.) Quantitative aspect of ruminant digestion and metabolism. Cambrige: Commonwealth Agricultural Bureux, 1993. p.383-403.

HANKINS, O.G.; HOWE, P.E. Estimation of the composition of beef carcasses and cuts. Washington: USDA, 1946. 20p (USDA. Technical Bulletin, 926).

HENRIQUE, W.; LEME, P.R.; LANNA, D.P.D. et al. Substituição do milho pela polpa de citrus em dietas de bovinos confinados. I. Desempenho animal. In: REUNIÃO ANUAL DA SOCIEDADE BRASILEIRA DE ZOOTECNIA, 33., Fortaleza, 1996. Anais. Fortaleza, SBZ, 1996. p. 58-60. 
HENRIQUE, W.; LEME, P. R.; LANNA, D.P.D et al. Avaliação do milho úmido com bagaço de cana ou silagem de milho na engorda de bovinos. I. Desempenho animal e características da carcaça. In: REUNIÃO ANUAL SOCIEDADE BRASILEIRA DE ZOOTECNIA, 36., Porto Alegre, 1999. Anais. Porto Alegre: SBZ, 1999a. p.307.

HENRIQUE, W.; LEME, P.R.; LANNA, D.P.D. et al. Equações para estimativa da composição química corporal de bovinos Santa Gertrudis a partir do corte da $9^{\text {a }}$ $10^{\mathrm{a}}-11^{\mathrm{a}}$ costelas. In: REUNIÃO DA SOCIEDADE BRASILEIRA DE ZOOTECNIA, 36., Porto Alegre, 1999. Anais. Porto Alegre: SBZ, $1999 \mathrm{~b}$.

HOPPER, T. H. Methods of estimating the physical and chemical composition of cattle. Journal of Agricultural Research, v. 68, p. 6, 1944.

KEARL, L. C. Nutrient requeriments of ruminants in developing countries. Lugan: Utah University, Agricultural Experiment Station, International Feedstuffs Institute, 1982. $271 \mathrm{p}$.

KEMPSTER, T.; CUTHBERTSON, A., HARRINGTON, G. Carcasse evaluation in livestock breeding: production and marketing. Boulder: Westview Press, 1982.

KUNKLE, W.E.; TETTER, AW.; PRESTON,R.L. Effect of diet on in vitro and in vivo rumen lactate disappearance rate in sheep. Journal of Animal Science, v.42, p.1256-1262, 1976.

LANA, R.P.; FONTES, C.A.A.; PERON, A.J, et al. Composição corporal e do ganho de peso e exigências de energia, proteína e macroelementos minerais $(\mathrm{Ca}, \mathrm{P}, \mathrm{Mg}$ e K) de novilhas de cinco grupos raciais. Conteúdo corporal e do ganho de peso em gordura, proteína e energia. Revista da Sociedade Brasileira de Zootecnia ,v.21, p. $518,1992$.

LANNA, D. P. D. Estimativa da composição química do corpo vazio de tourinhos Nelore através da gravidade específica da carcaça e da composição de cortes das costelas. Piracicaba, 1988. 131 p. Dissertação (Mestrado) - Escola Superior de Agricultura "Luiz de Queiroz", Universidade de São Paulo. 
LANNA, D.P.D.; FOX, D.G.; BOIN, C. Validation of the Cornell net carbohydrate and protein system estimates of nutrient requirements of growing and lactating zebu germplasm in tropical conditions. Journal of Animal Science, v.72, suppl.1, p.287, 1996.

LANNA, D.P.D.; FOX, D.G.; TEDESCHI, L.O. Exigências nutricionais de gado de corte: o sistema NRC. In: SIMPÓSIO SOBRE PRODUÇÃO INTENSIVA DE GADO DE CORTE, Campinas, 1998. Anais. Campinas: CBNA, 1998. p138167.

LANNA, D.P.D.; TEDESCHI, L.O.; BELTRAME FILHO, J.A. Modelos lineares e não-lineares de uso de nutrientes para formação de dietas de ruminantes. Scientia Agricola, v. 56, n.2, p.479-488, abr./jun. 1999.

LANNA, D.P.D.; BOIN, C.; ALLEONI, G.F. et al. Estimation of carcass and empty body composition of zebu bulls using the composition of rib cuts. Scientia Agricola, v.52, n.1, p. 189-197, 1995.

LANNA, D.P.D.; LEME, P.R.; BOIN, C. et al. Ganho compensatório de bovinos de diferentes grupos genéticos: composição química e fisica corporal. In: REUNIÃO DA SOCIEDADE BRASILEIRA DE ZOOTECNIA, 34., Juiz de Fora, 1997. Anais. Juiz de Fora: SBZ, 1997. P 352-354

LANNA, D.P.D.; MORAIS, J.P.; BOIN, C. et al. Desempenho e composição corporal de novilhas alimentadas com dois níveis de concentrado e bagaço de cana submetidos a diferentes processos de hidrólise. Revista Brasileira de Zootecnia, v.2, p.412-420, 1998.

LEME, P.R.; BOIN, C.; ALLEONI, G.F. et al. Estimativa da composição química corporal de novilhos Nelore através do espaço de deutério. Revista da Sociedade Brasileira de Zootecnia, v.26, n.3, p.351-362, 1994.

LEME, P.R.; HENRIQUE, W.; LANNA, D.P.D. et al. Subproduto concentrado da produção de lisina na alimentação de tourinhos em confinamento. 2 . Composição química corporal e do ganho de peso e taxas de deposição dos tecidos. In: REUNIÃO ANUAL SOCIEDADE BRASILEIRA DE ZOOTECNIA, 36., Porto Alegre, 1999. Anais. Porto Alegre: SBZ, 1999. p.340. 
LEME, P.R.; LANNA, D.P.D.; HENRIQUE, W. et al. Substituição do milho pela polpa de citrus em dietas de bovinos confinados. II. Composição química corporal e taxas de deposição. In: SOCIEDADE BRASILEIRA DE ZOOTECNIA, 34. Juiz de Fora, 1997. Anais. Juiz de Fora: SBZ, 1997 p 358360

LOERCH, S.C. Efficacy of plastic pot scrubbers as a replacement for roughage in high-concentrate cattle diets. Journal of Animal Science, v.69, p.2321-2328, 1991.

LOERCH, S.C; FLUHARTY, F.L. Effects of corn processing, dietary roughage level, and timing of roughage inclusion on performance of feedlot steers. Journal of Animal Science, v.76, p.681-685, 1998.

LUSH, J.L. Pratical methods of estimating the proportions of fat and bone in cattle slaughtered in commercial packing plants. Journal of Agricultural Research, v.32, p. 727-755, 1926.

MEDEIROS, S.R. Efeito da substituição do bagaço de cana-de-açúcar autohidrolizado por sorgo na fermentação ruminal de bovinos, digestibilidade in vivo em ovinos e desempenho animal em bovinos em acabamento. Piracicaba, 1989. 104p. Dissertação (Mestrado) - Escola Superior de Agricultura "Luiz de Queiroz”, Universidade de São Paulo.

NATIONAL RESEARCH COUNCIL. Nutrient requeriments of beef cattle. Washington: National Academy of Science, 1984. 90p.

NATIONAL RESEARCH COUNCIL Nutrient requeriments of beef cattle. 7.ed. Washington: National Academy of Science, 1996. 242p.

OWENS, F.N.; SECRIST, D.S.; HILL, W.J. et al.. Acidosis in cattle: a review. Journal of Animal Science, v. 76, p.275-286, 1998.

PACOLA, L.; CAIELLI, E.L.; MATTOS, J.C.A Bagaço de cana-de-açúcar na engorda de bovinos confinados. Boletim da Ind. Anim. v. 41, p.57-61, 1984.

PACOLA, L.; RAZOOK, AG.; LIMA, F.P. Aproveitamento do bagaço de cana-deaçúcar na engorda de bovinos confinados. Boletim da Ind. Anim., v.34, p.25$28,1977$. 
PRESTON, R.L. Mechanically programmed feeding system and application: step-up programs. In: SYMPOSIUM: INTAKE BY FEEDLOT CATTLE, 1995. Oakland State University, Oakland Agricultural Experiment Station, Div. Agric. Sci. Natural Res., 1995. p. 181-184.

PRESTON, R.L. Management of high concentrate Diets in feedlot. In: CONGRESSO BRASILEIRO DE NUTRIÇÃO ANIMAL, Campinas, 1998. Anais. Campinas: CBNA, 1998. p.82-91.

REID, J.T., WELLINGTON, G.H., DUNN, H.O. Some relationships among the major chemical components of the bovine body and their application to nutritional investigations. Journal of Dairy Science, v.38, p. 1344, 1955.

REID, J. T.; BENSADOUN, A.; BULL, L. S. et al. Some peculiarities in the body composition of animals. In: NATIONAL ACADEMY OF SCIENCES. Body composition of animals and man. Proc. Sym., University of Missouri, Columbia, 19-44, 1968.

RIBEIRO, F.G.; LEME, P.R.; BULLE, M.L.M.; et al. Características da carcaça e qualidade da carne de tourinhos alimentados com dietas de alta energia. 2000 (no prelo)

ROBELIN, J., GEAY, Y. Body composition of cattle as affected by physiological status, breed, sex and diet. In: GILCHRIST, F.M.C.; MACKIE, R.I. Herbivore nutrition in the subtropics and tropics. Pretoria: The Science Press, 1983. p. 525-548.

SAS INSITUTE. SAS/STAT: user's guide. Cary, 1997.

SIMPFENDORFER, S. Relationship of body type and size, sex and energy intake to the body composition of cattle. Ithaca, 1974. 193p. Thesis (PhD) - University of Cornell.

SNIFFEN,C.J.; O'CONNOR,J.D; VAN SOEST, P. J. A net carbohydrate and protein system for evaluating cattle diets. II. Carbohydrate and protein availability. Journal of Animal Science, v.70, p.3562-3577,1992.

TAYLOR, J.D.; ESDALE, W.J. Increased utilization of crop residues as animal feed through autohydrolysis. Ottawa: Stake Technology,1980. 
THIAGO, L.R.L.S.; SILVA, J.M.; COSTA, F.P., et al. Engorda de novilhos em confinamento utilizando subprodutos de microdestilarias de álcool. In: REUNIÃO ANUAL DA SOCIEDADE BRASILEIRA DE ZOOTECNIA, 20, Pelotas, 1983. Anais. Pelotas: SBZ, 1983 p100.

VAN SOEST, P. J. Nutritional ecology of the ruminant. 2.ed. Ithaca: Cornell

University Press, 1994 p 476.

VANCE, R.D., OCKERMAN, H.W., CAHILL, V.R. et al. Chemical composition as related to selected measurements used in beef carcass evaluation. Journal of Animal Science, v.33, p.4, 1971.

WALKER, H.G. Physical treatment. In: SUNDSTOL, F.; OWEN, E. Straw and other fibrous by-products as feed. Amsterdan: Elsevier Science, 1984. p. 79105

WOODY, H.D.; FOX, D.G.; BLACK, J.R. Effect of diet grain content on performance of growing and finishing cattle. Journal of Animal Science, v.57, p. 717-26, 1983.

XIONG, Y.; BARTLE, S.J.; PRESTON, R,L. Density of steam flaked sorghum grain, roughage level, and feeding regime for feedlot steers. Journal of Animal Science, v.69, 1707-1718, 1991. 